Article

\title{
Synthesis, Bacteriostatic and Anticancer Activity of Novel Phenanthridines Structurally Similar to Benzo[c]phenanthridine Alkaloids
}

\author{
Pavel Lasák ${ }^{1}$, Kamil Motyka ${ }^{2}$, Vladimír Kryštof ${ }^{3}$ (D) and Jakub Stýskala $^{1, *(D)}$ \\ 1 Department of Organic Chemistry, Faculty of Science, Palacký University, 17. Listopadu 1192/12, \\ CZ-771 46 Olomouc, Czech Republic; pavellasak@seznam.cz \\ 2 Institute of Molecular and Translation Medicine, Faculty of Medicine, Palacký University, Hněvotínská 5 , \\ CZ-779 00 Olomouc, Czech Republic; kamil.motyka@gmail.com \\ 3 Laboratory of Growth Regulators, Faculty of Science, Palacký University and Institute of Experimental \\ Botany ASCR, Šlechtitelů 27, CZ-783 71 Olomouc, Czech Republic; vladimir.krystof@upol.cz \\ * Correspondence: jakub.styskala@upol.cz; Tel.: +42-058-563-4466
}

Received: 31 July 2018; Accepted: 24 August 2018; Published: 27 August 2018

\begin{abstract}
In this study, we report the synthesis, antibacterial and anticancer evaluation of 38 novel phenanthridines that were designed as analogs of the benzo[c]phenanthridine alkaloids. The prepared phenanthridines differ from the benzo[c]phenanthridines in the absence of a benzene A-ring. All novel compounds were prepared from 6-bromo-2-hydroxy-3-methoxybenzaldehyde in several synthetic steps through reduction of Schiff bases and accomplished by radical cyclization. Twelve derivatives showed high antibacterial activity against Bacillus subtilis, Micrococcus luteus and/or Mycobacterium vaccae at single digit micromolar concentrations. Some compounds also displayed cytotoxicity against the K-562 and MCF-7 cancer cell lines at as low as single digit micromolar concentrations and were more potent than chelerythrine and sanguinarine. The active compounds caused cell-cycle arrest in cancer cells, increased levels of p53 protein and caused apoptosis-specific fragmentation of PARP-1. Biological activity was connected especially with the presence of the $N$-methyl quaternary nitrogen and 7-benzyloxy substitution (compounds $7 \mathbf{i}, 7 \mathbf{j}, 7 \mathbf{k}$, and 7l) of phenanthridine.
\end{abstract}

Keywords: phenanthridines; benzo[c]phenanthridines; radical cyclization; antiproliferative; antibacterial activity

\section{Introduction}

Benzo[c]phenanthridine alkaloids contain a chrysene-skeleton-based heterocyclic core and are classified as isoquinoline alkaloids (Figure 1). They are distributed especially in the plant family Papaveraceae and display a broad spectrum of biological activities, including anti-inflammatory, antimicrobial, antifungal and antitumor effects [1-7]. Sanguinarine and chelerythrine are the best-known benzo[c]phenanthridine alkaloids, most frequently studied for their antitumor effects [8]. As flat polyaromatic compounds they directly interact with DNA [9]. However, cell cycle arrest and induction of cell death caused by these alkaloids probably occurs not only due to DNA damage alone, but as a combined result of targeting other cellular structures, including topoisomerases, tubulin and antiapoptotic protein $\mathrm{Bcl}-\mathrm{X}_{\mathrm{L}}[10,11]$. Importantly, these alkaloids act at concentrations comparable to those of cytostatics used as anticancer drugs. 
<smiles></smiles>

Naturally occuring:

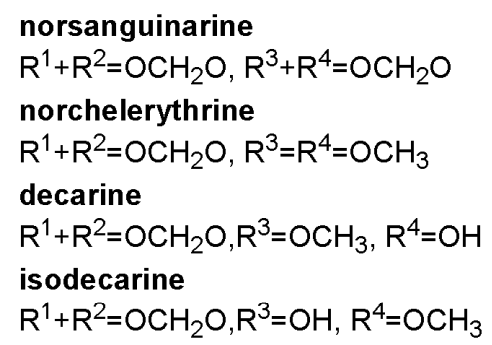

\section{Synthetic:}

13 $\mathrm{R}^{1}+\mathrm{R}^{2}=\mathrm{OCH}_{2} \mathrm{O}, \mathrm{R}^{3}=\mathrm{OBn}, \mathrm{R}^{4}=\mathrm{OCH}_{3}$,<smiles></smiles>

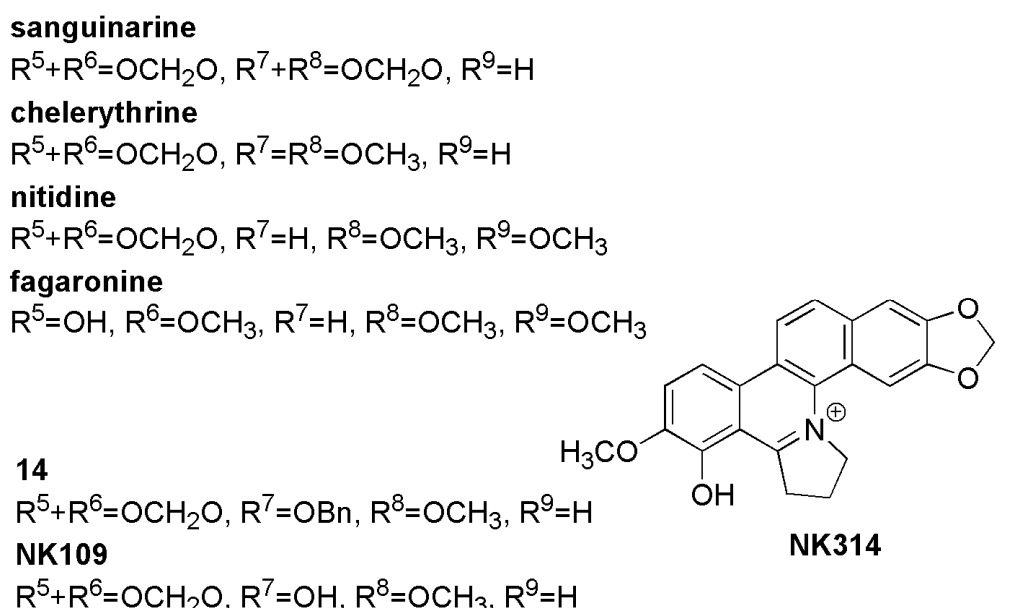

Figure 1. Structures of some benzo[c]phenanthridines.

Benzo[c]phenanthridine alkaloids have been subjected to chemical modifications with the aim of understanding their structure-activity relationships and to improve their biological functions. Early studies indicated that the activity of benzo[c]phenanthridine alkaloids can be linked to the presence of their cationic quaternary nitrogen [12]. The quaternary iminium may undergo nucleophilic addition to biological amines or thiols, modify DNA and proteins and as a consequence induce cell death. In contrast, a recent report suggests that the iminium group is not essential for cytotoxicity in cancer cell lines [13]. Other systematic studies examined the correlation between the type of substituents at positions 2, 3, 7, 8 and 9 of their skeletons and antiproliferative activity [14] and revealed that cationic iminium alkaloids displayed stronger activity than their corresponding uncharged bases. The cytotoxic activity was further increased if these quaternary bases were 7,8-oxygenated [15].

These studies led to identification of NK109, the 7-O-demethylated synthetic analogue of chelerythrine, that was shown to have submicromolar dose growth-inhibitory activity against cancer cell lines, i.e., significantly lower than chelerythrine [16-19] (Figure 1). Further modification of NK109, in which ring $C$ was fused to a pyrrolidine cycle, yielded NK314 with even stronger activities in several cancer models [20-22]. The molecular mechanism of action of these compounds has been often attributed to inhibition of topoisomerases, which are also targeted by the related compounds nitidine and fagaronine [23].

To our knowledge, there have not been many attempts to modify the heterocyclic skeleton of benzo[c]phenanthridines up until now in order to modify their biological activity. With the exception of benzo[ $h]$ quinolones, which are structurally related to the benzo[c]phenanthridines but lack the D-ring [24], and phenanthridines lacking the A-ring [25], most other reports describe the synthesis of various isomeric and aza-analogous structures such as benzo[i]phenanthridines and dibenzo[c,h]cinnolines [26], benzo[c]phenanthrolines [27], pyridophenanthrolines and azapyrimido-phenanthrolines [28] or compounds containing the 3,4-dihydroisoquinolin-2-ium scaffold [29,30].

We therefore decided to prepare novel phenanthridines related to benzo[c]phenanthridines lacking the benzene A-ring (Figure 2), because previous work has suggested that phenanthridines may 
retain biological activity [25]. The series contains derivatives differing in the presence and position of hydroxy and methoxy groups, 2,3- or 3,4-methylenedioxy bridges and 7-benzyloxy groups, but all compounds contain an 8-methoxy group. Some derivatives have been prepared either as free bases or protonated salts. In some compounds, the heterocyclic nitrogen is available in a quaternary form with methyl substitution. Thus, such variability allowed us to build a preliminary structure-activity relationship for antibacterial and antiproliferative activity, and to compare the phenanthridines with known benzo[c]phenanthridines (Figure 1).

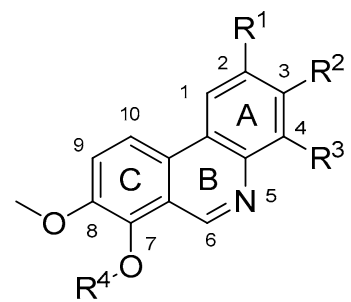<smiles>[R]Oc1c(OC)ccc2c1c[n+](C)c1c([R])c([R])c([R])cc21</smiles>

$R^{1}, R^{2}, R^{3}=H, O M e, R^{1}+R^{2}$ or $R^{2}+R^{3}=\mathrm{OCH}_{2} \mathrm{O} ; R^{4}=H, M e, B n ; X=I, C l, \mathrm{ClO}_{4}, \mathrm{HSO}_{4}, \mathrm{NO}_{3}$,

Figure 2. Desired phenanthridines for biological evaluation (for details see Table 1).<smiles></smiles>

1a: $R^{1}=$ OMe; $R^{2}=O M e ; R^{3}=H$

1b: $R^{1}=H ; R^{2}=O M e ; R^{3}=O M e$

1c: $\mathrm{R}^{1}+\mathrm{R}^{2}=\mathrm{OCH}_{2} \mathrm{O} ; \mathrm{R}^{3}=\mathrm{H}$

1d: $R^{1}=H ; R^{2}+R^{3}=O^{2} \mathrm{CH}_{2} \mathrm{O}$<smiles>[R]Oc1c(OC)ccc(Br)c1C=O</smiles>

2a: $\mathrm{R}^{4}=\mathrm{H}$

2b: $R^{4}=\mathrm{Me}$

2c: $R^{4}=B n$

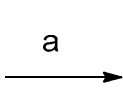<smiles>[R]Oc1c(OC)ccc(Br)c1/C=N/c1ccc([R])c([R])c1[R]</smiles><smiles>[R]Oc1c(CNc2ccc([R7])c([R])c2[R])ccc(Br)c1CNc1ccc(OC)c(OC)c1O[R]</smiles>

Scheme 1. The synthetic route for the preparation of phenanthridine derivatives. Reagents and conditions: (a) EtOH, reflux, 1 h; (b) $\mathrm{NaBH}_{4}, \mathrm{EtOH}$, r.t., 2 h; (c) $\mathrm{NaBH}(\mathrm{OAc})_{3}$, toluene, r.t., 1 h; (d) $\mathrm{Bu}_{3} \mathrm{SnH}$, AIBN, toluene, $104-106{ }^{\circ} \mathrm{C}, 3-6 \mathrm{~h}$; (e) activated $\mathrm{MnO}_{2}$, r.t., $18 \mathrm{~h}$; (f) $\mathrm{HCl}$, dioxane, r.t.; (g) MeI, $\mathrm{ACN}$, r.t., 7 days; (h) $\mathrm{NaOH}, \mathrm{EtOH}$, r.t., 1 h; (i) $\mathrm{HX}$, r.t., $10 \mathrm{~min}$. 
Table 1. Numbering of compounds 3-7.

\begin{tabular}{|c|c|c|c|c|c|c|c|c|c|}
\hline \multicolumn{5}{|c|}{ Compound Number } & & \multicolumn{4}{|c|}{ Type of Substitution } \\
\hline 3 & 4 & 5 & 6 & 7 & & $\mathbf{R}^{1}$ & $\mathbf{R}^{2}$ & $\mathbf{R}^{3}$ & $\mathbf{R}^{4}$ \\
\hline$\bullet$ & $\begin{array}{l}\bullet \\
\bullet \\
\bullet \\
\bullet \\
\bullet \\
\bullet \\
\bullet \\
\bullet \\
\bullet \\
\bullet \\
\bullet\end{array}$ & & & & $\begin{array}{l}\text { a: } \\
\text { b: } \\
\text { c: } \\
\text { d: } \\
\text { e: } \\
\text { f: } \\
\text { g: } \\
\text { h: } \\
\text { i: } \\
\text { j: } \\
\text { k: } \\
\text { l: }\end{array}$ & $\begin{array}{c}-\mathrm{OCH} \\
\mathrm{H} \\
-\mathrm{C} \\
\mathrm{H} \\
-\mathrm{OCH} \\
\mathrm{H} \\
-\mathrm{C} \\
\mathrm{H} \\
-\mathrm{OCH} \\
\mathrm{H} \\
-\mathrm{C} \\
\mathrm{H}\end{array}$ & $\begin{array}{l}-\mathrm{OCH}_{3} \\
-\mathrm{OCH}_{3} \\
{ }_{2} \mathrm{O}- \\
-\mathrm{OCH} \\
-\mathrm{OCH}_{3} \\
-\mathrm{OCH}_{3} \\
{ }_{2} \mathrm{O}- \\
- \\
-\mathrm{OC} \\
-\mathrm{OCH}_{3} \\
-{ }_{2} \mathrm{OC} \mathrm{CH}_{3} \\
\end{array}$ & $\begin{array}{c}\mathrm{H} \\
-\mathrm{OCH} \\
\mathrm{H} \\
\mathrm{I}_{2} \mathrm{O}- \\
\mathrm{H} \\
-\mathrm{HCH}_{3} \\
\mathrm{H} \\
\mathrm{I}_{2} \mathrm{O}- \\
\mathrm{H} \\
-\mathrm{HCH}_{3} \\
\mathrm{H} \\
{ }_{2} \mathrm{O}-\end{array}$ & $\begin{array}{c}\mathrm{H} \\
\mathrm{H} \\
\mathrm{H} \\
\mathrm{H} \\
\mathrm{CH}_{3} \\
\mathrm{CH}_{3} \\
\mathrm{CH}_{3} \\
\mathrm{CH}_{3} \\
\text { benzyl } \\
\text { benzyl } \\
\text { benzyl } \\
\text { benzyl }\end{array}$ \\
\hline
\end{tabular}

- Newly prepared compounds (for general structures see Scheme 1).

For the preparation of novel phenanthridine derivatives we adapted methodologies from benzo[c]phenanthridine chemistry. Many synthetic approaches to the benzo[c]phenanthridine nucleus have been reported, with most routes involving the construction of either the $\mathrm{B}$ or $\mathrm{C}$ ring in the final or semifinal stage. These synthetic methods are summarized in reviews [31,32]. Our synthesis of desired phenanthridine compounds is based on our previous experience with the synthesis of isodecarine [33] and metabolites of benzo[c]phenanthridines [34], where a radical cyclization leading to ring C closure was used to accomplish the construction of the benzo[c]phenanthridine heterocyclic system. By this method we prepared phenanthridine derivatives where the B ring is formed.

\section{Results and Discussion}

\subsection{Chemistry}

For the preparation of phenanthridines, selected anilines possessing substitution in positions 2,3 (1b [35], 1d [36]) and 3,4 (1a, 1c) with methylenedioxy or dimethoxy groups were used for the reactions. Commercially available 6-bromo-2-hydroxy-3-methoxybenzaldehyde (2a) needed for introduction of the C-ring aromatic core was used as is or after modification of the hydroxyl group to obtain the methoxyaldehyde $\mathbf{2 b}$ [25] or benzyloxyaldehyde $\mathbf{2} \mathbf{c}$ [16].

Reductive amination of aldehydes $\mathbf{2} \mathbf{a}-\mathbf{2} \mathbf{c}$ with selected anilines $\mathbf{1 a}-\mathbf{1} \mathbf{d}$ by $\mathrm{NaBH}(\mathrm{OAc})_{3}$ in toluene proceeded quantitatively and afforded the corresponding novel secondary amines 4 . We have also verified an alternative two-step route leading to the same secondary amines through their isolated Schiff bases $\mathbf{3}$. The preparation of Schiff bases $\mathbf{3 a}, \mathbf{3} \mathbf{c}$, and $\mathbf{3 d}$ possessing unsubstituted hydroxyl groups proceeded smoothly providing products that readily precipitated from the reaction mixture with excellent nearly quantitative yields. Facile reduction of their iminium double bonds by $\mathrm{NaBH}_{4}$ in ethanol led to the corresponding secondary amines $\mathbf{4 a}, \mathbf{4 c}$, and $\mathbf{4 d}$. Surprisingly, the condensation leading to the formation of Schiff bases with substituted hydroxyl group $\left(\mathrm{R}^{4}=\right.$ benzyl or methyl $)$ under the same reaction conditions was not quantitative (conversions ranged from 50-75\%) and subsequent isolation attempts by conventional methods were complicated. Therefore, we tried to influence the reaction equilibrium by increasing the ratio of aniline to aldehyde, prolonging the reaction time, performing the reactions in alternative solvents or by use of a microwave reactor, but unfortunately, without any satisfactory improvement. In summary, reductive amination seems to be a more suitable method for the preparation of these sorts of amines 4.

To obtain compounds possessing a phenanthridine core, amines 4 needed to be cyclized. For this purpose, several synthetic approaches including palladium-catalyzed cross-coupling cyclization [37-41] or base-promoted homolytic aromatic substitution [42,43] were tested with amines 
4a and 4e, unfortunately, the reactions failed or yields were very low. During these experiments debromination was the main reaction observed. Finally, radical cyclization by $\mathrm{Bu}_{3} \mathrm{SnH}$ using AIBN (azobisisobutyronitrile) as a radical initiator in toluene and subsequent aromatization by activated $\mathrm{MnO}_{2}$ [44] afforded the desired novel phenanthridine derivatives 5 in various yields. During all radical cyclization reactions we observed formation of debrominated starting amines $\mathbf{1 0}$ as side products in amounts of $10-20 \%$ (Scheme 2). Formation of these reduced compounds is in accordance with earlier results [33]. Further side products were detected when 3,4-disbstituted $\left(R^{1}\right.$ and $\left.R^{2}\right)$ amines 4 were subjected to the radical cyclization conditions. Apart from reduced amines 10, cyclized regioisomers 11 were also observed as minor products. In the case of substituted amines 4 , where $\mathrm{R}^{4}$ is benzyl or methyl the amount of $\mathbf{1 1}$ was around 5\%, whereas the ratio of these regioisomers was much higher (up to $30 \%$, based on HPLC analysis) for the unsubstituted hydroxylamines $4 \mathbf{a}-\mathbf{4 d}$ (Scheme 2).<smiles>[R]Oc1c(OC)ccc(Br)c1CNc1cccc([R])c1[R]</smiles>

4<smiles>[R]Oc1c(OC)ccc(Br)c1CNc1ccc([R])c([R])c1</smiles><smiles>[R]C1=CC=C2C(=CC=C(OC)C(OC)=C2[R])N=C1[R]</smiles>

5<smiles>[R]Oc1c(CNc2cccc([R])c2[R])cccc1OC</smiles>

minor 10<smiles>[R]Oc1c(CNc2ccc([R1])c([R])c2)cccc1OC</smiles>

Scheme 2. Side reaction products formed during radical cyclization of 4 to 5 . Reagents and conditions: (a) $\mathrm{Bu}_{3} \mathrm{SnH}, \mathrm{AIBN}$, toluene, $104-106{ }^{\circ} \mathrm{C}, 3-6 \mathrm{~h}$; (b) activated $\mathrm{MnO}_{2}$, r.t., 18 h.

Crystallization was utilized here as a useful method for the separation of most phenanthridines $\mathbf{5}$ from their reaction by-products. Unfortunately, a problem concerning the isolation of pure compounds was observed with hydroxyphenanthridines $\mathbf{5 a}-\mathbf{5} \mathbf{d}$. The byproducts formed had similar properties to the targeted molecules, with only silica gel column chromatography providing pure compound $\mathbf{5 d}$, but again with difficulties. For these reasons the remaining hydroxyphenanthridines $\mathbf{5 a - 5} \mathbf{c}$ were obtained by catalytic hydrogenation of the corresponding benzyl derivatives $\mathbf{5 i - 5 k}$. This benzyl group deprotection proceeded under atmospheric pressure of hydrogen on $10 \% \mathrm{Pd} / \mathrm{C}$. Under these conditions reduction of the iminium double bond can occur, so subsequent stirring of the reaction mixture in air or by addition of $\mathrm{MnO}_{2}$ was necessary for rearomatization. Alternatively, to avoid the need for this re-oxidation step benzyl group removal could also be achieved by acid hydrolysis with $\mathrm{HCl}$ followed by treatment with aqueous $\mathrm{NH}_{3}$ to obtain the free bases (Scheme 3).

Phenanthridine derivatives 5 were converted to their hydrochlorides 6 by addition of $\mathrm{HCl}$ into dioxane solutions of the free bases (Scheme 1). Surprisingly these compounds have very low solubility in water, and even in other polar solvents (DMSO, EtOH, DMF) which hindered biological testing.

$\mathrm{N}$-methylation of phenanthridines $\mathbf{5}$ was carried out with methyl iodide in acetonitrile under mild conditions to give $\mathrm{N}$-methylphenanthridinium iodides 7 . These conditions enabled the selective methylation, even of the phenanthridines possessing a free hydroxyl group. Similarly to the hydrochlorides 6 , the prepared quaternary iodides 7 were also surprisingly very poorly soluble in water. To verify the possibility if the anion exchange can influence the solubility of these compounds, selected quaternary iodides were transformed in a $\mathrm{NaOH} / \mathrm{EtOH}$ solution into their unisolated colorless pseudobases 8. Different salts (chloride, hydrogensulfate, perchlorate, and nitrate) were obtained by 
addition of large excess of corresponding acids to provide the anion modified $N$-methylphenanthridine precipitates. It was found that anion exchange did not improve solubility of these mentioned compounds significantly. For illustration, we demonstrate experimentally the preparation of various salts of compound $\mathbf{9}$, which were confirmed by elemental analysis.<smiles>[R]c1cc2c(cnc3c(OCc4ccccc4OC)c(OC)ccc32)c([R])c1CC</smiles>

$5 \mathrm{i}-5 \mathbf{k}$<smiles>[R]c1cc2c(c([R])c1[R])NCc1c-2ccc(OC)c1O</smiles>

$5 a-5 c$
12

Scheme 3. Convenient route for the preparation of hydroxy phenanthridines $\mathbf{5 a - 5 c . ~ R e a g e n t s ~ a n d ~}$ conditions: (a) $\mathrm{H}_{2} / 10 \% \mathrm{Pd}(\mathrm{C})$, atm. pressure, r.t. or $\mathrm{HCl} / \mathrm{EtOH}$, reflux $2.5 \mathrm{~h}$, then aq. $\mathrm{NH}_{3}$; (b) air $\left(\mathrm{O}_{2}\right)$ or $\mathrm{MnO}_{2}$; r.t.

\subsection{Biological Assays}

\subsubsection{Antibacterial Activity}

Prepared derivatives were screened for antibacterial activity against representative Gram-positive bacteria (Bacillus. subtilis, ATCC 6633; Micrococcus luteus, ATCC 10240; Mycobacterium vaccae, DSM 43514; Staphylococcus aureus, CCM 2524) and Gram-negative bacteria (Pseudomonas aeruginosa, CCM 3955; Escherichia coli, CCM 3954) using agar diffusion assays [45]. Derivatives with zones of inhibition $\geq 20 \mathrm{~mm}$ were subjected to a further assay [46] that determines their minimum inhibitory concentrations (MIC). From the measured data (Table 2) it is possible to make a few general conclusions regarding their structure-activity relationships:

(1) Antibacterial activity was observed only for derivatives containing a phenanthridine skeleton. No tested strain was susceptible to representative intermediates 3 and 4.

(2) Derivatives with benzyl substituent as $\mathrm{R}^{4}(\mathbf{5 k}, \mathbf{5 1}, \mathbf{7} \mathbf{i}, \mathbf{7} \mathbf{j}, \mathbf{7 k}$, and $\mathbf{7})$ showed high antibacterial activity against $B$. subtilis, M. luteus and/or M. vaccae with MIC in single digit micromolar values.

(3) Compounds with a charged nitrogen bearing methyl group $(\mathbf{7 i}, 7 \mathbf{j}, 7 \mathbf{k}$ and $\mathbf{7 1})$ demonstrated high activity as well. To summarize, the most active compounds have a similar structural motif-a phenanthridine skeleton with a charged $N$-methyl nitrogen and a benzyl group as a $\mathrm{R}^{4}$ substituent.

These points are noteworthy for potential structural exploitation in further antibacterial agent development. To compare the antibacterial activity results for well-known natural (chelerythrine, sanguinarine, isodecarine, norchelerythrine) or synthetic compounds (NK-109, 13, 14) with similar structure motifs are presented in Table 2 as well. From the measured results it is evident that some prepared derivatives provided similar or even better activity than these compounds (MIC in micromolar or submicromolar values). All newly reported compounds were less active than a previously developed analogue 14 , with $7 \mathrm{j}$ performing better than that reference compound only against $M$. luteus. No compound displayed any relevant activity against Gram-negative bacteria. If the structures are compared the importance of the presence of a charged $\mathrm{N}$-methyl nitrogen in the molecule is confirmed. 
Table 2. Antibacterial activity.

\begin{tabular}{|c|c|c|c|c|c|c|}
\hline \multirow[b]{2}{*}{ Compound } & \multicolumn{6}{|c|}{ Diameter of Inhibition Zone in Agar Diffusion Assay $(\mathrm{mm})(\mathrm{MIC})\left(\mu \mathrm{mol} \mathrm{L}{ }^{-1}\right)$} \\
\hline & $\begin{array}{c}\text { B. subtilis } \\
\text { (ATCC 6633) }\end{array}$ & $\begin{array}{c}\text { M. luteus } \\
\text { (ATCC 10240) }\end{array}$ & $\begin{array}{c}\text { M. vaccae } \\
\text { (DSM 43514) }\end{array}$ & $\begin{array}{l}\text { S. aureus } \\
\text { (CCM 2524) }\end{array}$ & $\begin{array}{l}\text { P. aeruginosa } \\
\text { (CCM 3955) }\end{array}$ & $\begin{array}{c}\text { E. coli } \\
\text { (CCM 3954) }\end{array}$ \\
\hline $5 a$ & 13 & 14 & 15 & 15 & 15 & 12 \\
\hline $5 \mathbf{b}$ & 12 & 15 & $20(>200)$ & 19 & $20(>200)$ & 0 \\
\hline $5 c$ & 18 & 17 & $25(50)$ & 18 & 16 & 0 \\
\hline $5 d$ & $33(50)$ & $22(50)$ & $23(25)$ & 18 & 15 & 0 \\
\hline $5 e$ & $22(>200)$ & 18 & $23(200)$ & 13 & 12 & 12 \\
\hline $5 f$ & $35(50)$ & $30(100)$ & $31(25)$ & $20(50)$ & 15 & 13 \\
\hline $5 \mathrm{~g}$ & 20(100) & 14 & 16 & 11 & 12 & 0 \\
\hline $5 \mathrm{~h}$ & $34(50)$ & $30(100)$ & $22(25)$ & $20(50)$ & 15 & 0 \\
\hline $5 i$ & $28(50)$ & $22(50)$ & 18 & 17 & 15 & 0 \\
\hline $5 j$ & 19 & 18 & 17 & 19 & 13 & 12 \\
\hline $5 \mathrm{k}$ & $41(6.25)$ & $33(3.13)$ & $31(12.5)$ & $24(25)$ & 16 & 11 \\
\hline 51 & $34(12.5)$ & $30(3.13)$ & $32(12.5)$ & $20(50)$ & 15 & 0 \\
\hline $6 e$ & 0 & 13 & 19 & 13 & 15 & 14 \\
\hline $6 f$ & 11 & 16 & 12 & 0 & 15 & 15 \\
\hline $6 \mathrm{~g}$ & 11 & 16 & 12 & 0 & 15 & 15 \\
\hline $6 h$ & 0 & 15 & 14 & 12 & 16 & 11 \\
\hline $6 \mathbf{i}$ & 14 & 16 & 13 & 11 & 18 & 0 \\
\hline $6 j$ & 11 & 16 & 12 & 0 & 18 & 10 \\
\hline $6 k$ & 12 & 15 & 14 & 14 & 17 & 0 \\
\hline 61 & 12 & 10 & 10 & 14 & 0 & 0 \\
\hline $7 \mathrm{c}$ & 13 & 20 & 10 & 15 & 0 & 0 \\
\hline $7 d$ & 13 & 19 & $21(100)$ & 15 & 0 & 0 \\
\hline $7 e$ & 11 & $26(50)$ & 11 & 12 & 14 & 13 \\
\hline $7 f$ & 13 & $36(25)$ & $21(50)$ & 17 & 13 & 12 \\
\hline $7 \mathrm{~g}$ & $39(6.25)$ & $48(12.5)$ & 18 & 15 & 14 & 12 \\
\hline $7 \mathrm{~h}$ & $26(25)$ & $40(50)$ & 15 & 14 & 15 & 11 \\
\hline $7 \mathrm{i}$ & $25(25)$ & $42(3.13)$ & $40(6.25)$ & 13 & 10 & 0 \\
\hline $7 \mathbf{j}$ & $35(12.5)$ & $42(0.78)$ & $40(12.5)$ & 13 & 12 & 0 \\
\hline $7 \mathbf{k}$ & $30(12.5)$ & $42(3.13)$ & $30(3.13)$ & $20(50)$ & 0 & 12 \\
\hline 71 & $30(25)$ & $37(3.13)$ & $30(3.13)$ & 18 & 0 & 0 \\
\hline $9 t$ & 15 & $25(50)$ & $21(50)$ & 15 & 10 & 10 \\
\hline $9 u$ & 15 & $20(25)$ & $25(50)$ & 18 & 13 & 10 \\
\hline $9 w$ & 17 & $20(50)$ & $21(50)$ & 17 & 10 & 12 \\
\hline $9 z$ & 15 & $33(25)$ & $21(50)$ & 17 & 13 & 10 \\
\hline 13 & 15 & 12 & 16 & 15 & 0 & 0 \\
\hline 14 & $25(0.78)$ & $22(6.25)$ & $23(0.78)$ & $24(0.78)$ & 0 & 15 \\
\hline norchelerythrine & 14 & 11 & 17 & 18 & 0 & 0 \\
\hline isodecarine & 16 & 11 & 12 & 16 & 0 & 0 \\
\hline NK-109 & $32(1.56)$ & $27(12.5)$ & $45(12.5)$ & $25(12.5)$ & 0 & 15 \\
\hline chelerythrine & $30(3.13)$ & $26(50)$ & $32(3.13)$ & $24(6.25)$ & 0 & 16 \\
\hline sanguinarine & $29(3.13)$ & $27(25)$ & $27(6.25)$ & $24(6.25)$ & 0 & 17 \\
\hline Ciprofloxacin * & $20(7.5)$ & $22(0.26)$ & $27(0.26)$ & $20(15.0)$ & $15(3.75)$ & $20(7.5)$ \\
\hline
\end{tabular}

* used as a standard.

\subsubsection{Anticancer Activity In Vitro}

Benzo[c]phenanthridine alkaloids are known to display antiproliferative and anticancer activities $[8,18]$. Due to their structural analogy, the preliminary in vitro anticancer activity of the newly prepared compounds was evaluated on two established cancer cell lines, MCF-7 (breast carcinoma) and K-562 (chronic myelogeneous leukemia). The resulting data are presented in Table 3 and show that several of the new compounds have significant activity in both cell lines, with single digit micromolar $\mathrm{EC}_{50}$ values. 
Table 3. Anticancer activity in vitro.

\begin{tabular}{|c|c|c|}
\hline \multirow{2}{*}{ Compounds } & \multicolumn{2}{|c|}{$\mathrm{EC}_{50}(\mu \mathrm{M}) *$} \\
\hline & K-562 & MCF-7 \\
\hline $3 a$ & $>50$ & $>50$ \\
\hline $3 c$ & $>50$ & $>50$ \\
\hline $3 d$ & $>50$ & $>50$ \\
\hline $4 a$ & $>50$ & $>50$ \\
\hline $4 c$ & $71 \pm 2$ & $79 \pm 1$ \\
\hline $4 d$ & $>50$ & $>50$ \\
\hline $4 e$ & $40 \pm 8$ & $70 \pm 5$ \\
\hline $4 \mathrm{f}$ & $>25$ & $>25$ \\
\hline $4 \mathrm{~g}$ & $51 \pm 5$ & $75 \pm 2$ \\
\hline $4 h$ & $>12$ & $>12$ \\
\hline $4 i$ & $>50$ & $>50$ \\
\hline $4 j$ & $>25$ & $>25$ \\
\hline $4 \mathrm{k}$ & $>50$ & $>50$ \\
\hline 41 & $>50$ & $>50$ \\
\hline $5 a$ & $11 \pm 1$ & $17 \pm 6$ \\
\hline $5 b$ & $40 \pm 5$ & $24 \pm 4$ \\
\hline $5 c$ & $59 \pm 4$ & $17 \pm 1$ \\
\hline $5 d$ & $19 \pm 6$ & $12 \pm 1$ \\
\hline $5 e$ & $29 \pm 6$ & $27 \pm 6$ \\
\hline $5 f$ & $13 \pm 1$ & $10 \pm 2$ \\
\hline $5 g$ & $8.7 \pm 1.3$ & $7.2 \pm 2.9$ \\
\hline $5 \mathrm{~h}$ & $14 \pm 1$ & $10 \pm 1$ \\
\hline $5 i$ & $19 \pm 8$ & $15 \pm 5$ \\
\hline $5 j$ & $36 \pm 11$ & $23 \pm 5$ \\
\hline $5 \mathrm{k}$ & $4.2 \pm 1.1$ & $3.2 \pm 0.9$ \\
\hline 51 & $>50$ & $>50$ \\
\hline $6 a$ & $8.7 \pm 1.2$ & $18 \pm 3$ \\
\hline $6 c$ & $60 \pm 8$ & $17 \pm 4$ \\
\hline $6 d$ & $>50$ & $>50$ \\
\hline $6 e$ & $24 \pm 1$ & $34 \pm 6$ \\
\hline $6 f$ & $82 \pm 7$ & $39 \pm 3$ \\
\hline $6 \mathrm{~g}$ & $15 \pm 3$ & $20 \pm 2$ \\
\hline $6 h$ & $59 \pm 12$ & $45 \pm 6$ \\
\hline $6 i$ & $67 \pm 18$ & $43 \pm 9$ \\
\hline $6 j$ & $14 \pm 1$ & $21 \pm 2$ \\
\hline $6 \mathrm{k}$ & $>50$ & $>50$ \\
\hline 61 & $>50$ & $>50$ \\
\hline $7 c$ & $82 \pm 10$ & $57 \pm 7$ \\
\hline $7 d$ & $41 \pm 4$ & $16 \pm 1$ \\
\hline $7 e$ & $>50$ & $38 \pm$ \\
\hline $7 f$ & $81 \pm 17$ & $69 \pm 7$ \\
\hline $7 \mathrm{~g}$ & $29 \pm 13$ & $11 \pm 6$ \\
\hline $7 \mathrm{~h}$ & $>50$ & $>50$ \\
\hline $7 \mathrm{i}$ & $6.4 \pm 1.1$ & $5.3 \pm 1.1$ \\
\hline $7 \mathbf{j}$ & $0.8 \pm 0.2$ & $2.6 \pm 0.3$ \\
\hline $7 \mathbf{k}$ & $5.1 \pm 0.7$ & $1.8 \pm 0.8$ \\
\hline 71 & $8.3 \pm 1.4$ & $7.7 \pm 0.9$ \\
\hline $9 t$ & $>50$ & $>50$ \\
\hline $9 u$ & $>50$ & $45 \pm 4$ \\
\hline $9 w$ & $>50$ & $36 \pm 9$ \\
\hline $9 z$ & $>50$ & $>50$ \\
\hline 13 & $94 \pm 6$ & $48 \pm 2$ \\
\hline 14 & $0.9 \pm 0.2$ & $1.4 \pm 0.1$ \\
\hline norchelerythrine & $>100$ & $>100$ \\
\hline isodecarine & $>100$ & $>100$ \\
\hline NK-109 & $1.0 \pm 0.1$ & $4.6 \pm 0.6$ \\
\hline chelerythrine & $8.6 \pm 1.8$ & $5.9 \pm 0.5$ \\
\hline sanguinarine & $2.2 \pm 0.2$ & $2.0 \pm 0.2$ \\
\hline cisplatin & $4.7 \pm 0.4$ & $11 \pm 1$ \\
\hline
\end{tabular}

* Values are means of triplicates and indicate concentration that kills 50\% of cells during a three-day cultivation. 
Derivative $7 \mathbf{j}$ reached submicromolar values in K-562 cells and was even more potent than chelerythrine and sanguinarine. The most active compounds bear 7-benzyloxy substitution and either 2,3-dimethoxy or an isosteric 2,3-methylenedioxy bridge and are either N5-methylated $(7 \mathbf{j}, 7 \mathbf{k})$ or contain an unsubstituted N5 (5k). Compounds without a benzyl moiety or with 3,4-dimethoxy/3,4-methylenedioxy substitution were less potent. Interestingly, removal of the methyl from $N 5$ of $\mathbf{7 j}$, that also uncharged the nitrogen, decreased potency (5j). In contrast, presence of the quaternary nitrogen (methylated) significantly reduced the activity of several compounds (compare especially pairs $5 f$ and $7 f, 5 g$ and $7 g$, $5 \mathrm{~h}$ or $7 \mathrm{~h}$ ). According to previous studies, the activity of benzo[c]phenanthridine alkaloids can be explained by the presence of a cationic quaternary nitrogen $[12,15]$. These conclusions however probably cannot be applied to phenanthridines, because many of these compounds with a quaternary nitrogen have poor activity and one of the most potent compounds (5k) does not contain a quaternary nitrogen at all.

With the aim of directly comparing the activity of phenanthridines with the corresponding benzo[c]phenanthridines, we prepared also four variously substituted benzo[c]phenanthridines-13 [16,33], 14 [33], isodecarine [33] and norchelerythrine (Figure 1). In line with the abovementioned findings for phenanthridines, the presence of the benzyloxy functionality at position 7 correlated with in vitro anticancer activity for compounds $\mathbf{1 3}$ and $\mathbf{1 4}$. However, previous studies indicated that the activity of benzo[c]phenanthridine alkaloids can be explained by the presence of a cationic quaternary nitrogen atom [12]. We also observed lack of cellular activity with isodecarine and norchelerythrine, which were prepared as demethylated derivatives of the very potent NK-109 and chelerythrine, respectively. Compound 14, killing both cancer cell lines with $\mathrm{EC}_{50}$ values around $1 \mu \mathrm{M}$, contains not only a benzyloxy functionality, but also a quaternary nitrogen that could be essential for its activity. We cannot rule out the possibility that this cation is even more important for the activity.

\subsubsection{Mechanism of Cellular Activity}

Anticancer activity of benzo[c]phenanthridine alkaloids relates at least partly to their ability to inhibit topoisomerase I or II. For example, nitidine and fagaronine inhibit the topoisomerase I-mediated DNA relaxation [23].

Their synthetic derivatives NK109 and NK314 exerted their cytotoxic activity through inhibition of topoisomerase II, followed by DNA breaks [19,22]. DNA damage usually results in a cell cycle arrest and eventually leads to apoptosis. We therefore treated MCF-7 cells with several compounds and NK109 as a control. Interestingly, these compounds influenced the cell cycle profile in different manners (Figure 3). The most potent $7 \mathrm{k}$ reduced $\mathrm{S}$ and $\mathrm{G} 2 / \mathrm{M}$ phases, $7 \mathrm{~g}$ reduced $\mathrm{S}$ phase and caused slight accumulation in $\mathrm{G} 2 / \mathrm{M}$, whereas the only weakly cytotoxic $\mathbf{6 g}$ resulted in strong $\mathrm{G} 2 / \mathrm{M}$ arrest. NK109 used as a control also arrested cells in G2/M. These differences suggest that the compounds may have different molecular targets.

DNA damage induces various responses, including stabilization and activation of tumor suppressor protein p53 [47]. In the following experiments, we analyzed levels and activities of tumor suppressor protein p53, which is typically activated in cells upon topoisomerase inhibition. We performed immunoblotting of proteins extracted from MCF-7 cells treated for $24 \mathrm{~h}$ with compounds $6 \mathrm{~g}, 7 \mathrm{k}$ and $7 \mathrm{~g}$. Levels of $\mathrm{p} 53$ and its typical downstream target $\mathrm{p} 21^{\text {waf1 }}$ were both increased (Figure 4). In addition, fragmentation of PARP producing a $89 \mathrm{kDa}$ band was observed in cells treated with 7k and NK109, indicating ongoing apoptosis. This fragmentation was dose-dependent for compound $\mathbf{7 k}$. In contrast, neither $\mathbf{6 g}$ nor $\mathbf{7 g}$ triggered PARP fragmentation, which is in line with their weaker cytotoxicities. 

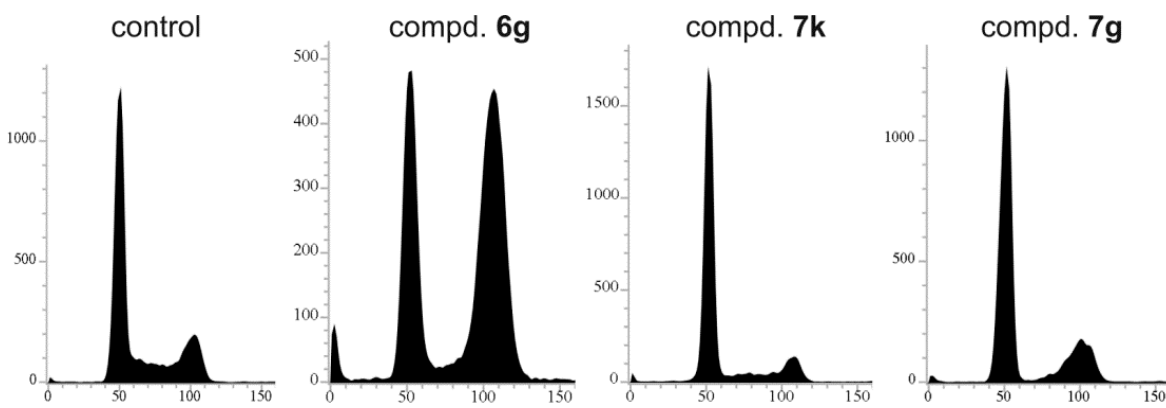

NK-109

Figure 3. Cell cycle effects of compounds $7 \mathbf{k}, 7 \mathbf{g}, \mathbf{6 g}$ and NK-109 in MCF-7 cells treated for $24 \mathrm{~h}$ with doses corresponding to $3 \times \mathrm{EC}_{50}$ values $(60,5.4,33$ and $13.8 \mu \mathrm{M}$, respectively). Cells were harvested and then flow cytometric analysis of DNA stained by propidium iodide (10,000 counts) was performed as described in the Materials and Methods section.

compound $7 \mathbf{k}$

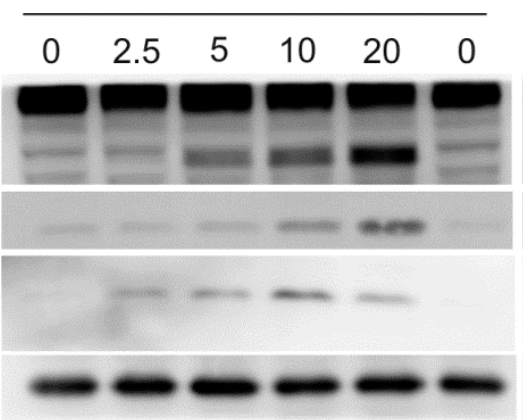

compound $6 \mathrm{~g}$

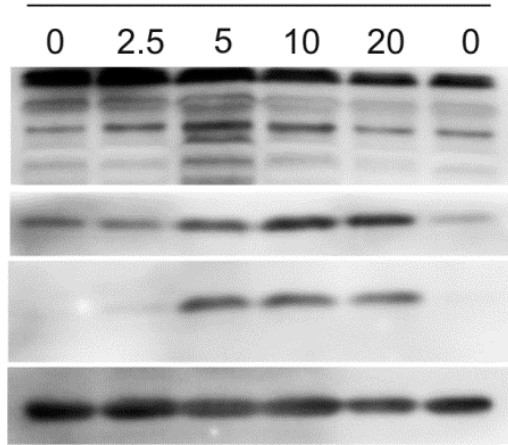

NK-109

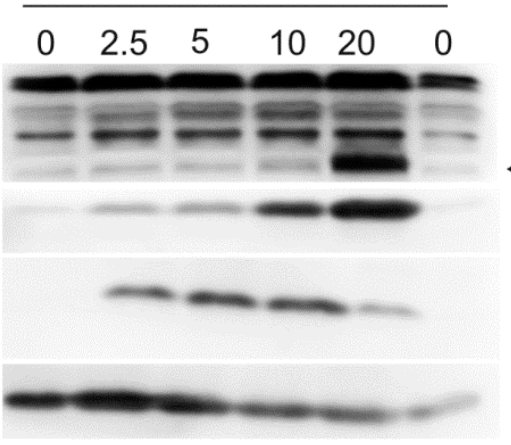

compound $7 \mathrm{~g}$

\begin{tabular}{llllll}
\hline 0 & 2.5 & 5 & 10 & 20 & 0 \\
\hline
\end{tabular}

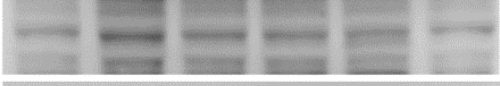

PARP

p53

p21WAF1

PCNA

Figure 4. Dose-dependent effect of compounds 7k, 7g, 6g and NK-109 on p53 and its activity in MCF-7 cells. The cells were treated for $24 \mathrm{~h}$ with indicated doses of compounds (given in $\mu \mathrm{M}$ ) and then specific proteins were analyzed by immunoblotting as described in the Materials and Methods section. C.f., $89 \mathrm{kDa}$ cleavage fragment of PARP.

\section{Materials and Methods}

\subsection{Chemistry}

\subsubsection{General Information}

All commercially available reagents were used without further purification and purchased from standard chemical suppliers. Reactions were monitored by LC/MS analyses on a UHPLC-MS system (Thermo Scientific, Waltham, MA, USA) consisting of a UHPLC chromatograph equipped with a photodiode array detector and a triple quadrupole mass spectrometer using a $\mathrm{C} 18$ column at $30{ }^{\circ} \mathrm{C}$ and 
flow rate of $800 \mu \mathrm{L} / \mathrm{min} .{ }^{1} \mathrm{H}$ and ${ }^{13} \mathrm{C}-\mathrm{NMR}$ spectra were measured on an ECA $400 \mathrm{II}\left({ }^{1} \mathrm{H}: 399.78 \mathrm{MHz}\right.$, ${ }^{13} \mathrm{C}$ : $100.53 \mathrm{MHz}$ ) NMR spectrometer (JEOL Resonance, Tokyo, Japan). Samples were dissolved and subsequently measured in DMSO- $d_{6}$ or $\mathrm{CDCl}_{3}$. Chemical shifts $(\delta)$ are reported in ppm and referenced to the middle of the solvent signal (DMSO- $d_{6}: 2.50 \mathrm{ppm}, 39.51 \mathrm{ppm} ; \mathrm{CDCl}_{3}: 7.27 \mathrm{ppm}$, $77.00 \mathrm{ppm}$. Data are reported as follows: chemical shift (multiplicity [singlet (s), doublet (d), doublet of doublet $(\mathrm{dd})$, triplet $(\mathrm{t})$, quartet $(\mathrm{q})$, multiplet $(\mathrm{m})$, broad resonance (br)], coupling constants [Hz], integration). All the NMR spectra were acquired at ambient temperature. All recorded ${ }^{1} \mathrm{H}$ and ${ }^{13} \mathrm{C}$-NMR spectra are available as Supplementary material. High resolution mass spectra (HRMS) measurements were performed on an Orbitrap mass analyzer (Thermo Scientific, Waltham, MA, USA) equipped with Heated Electrospray Ionization (HESI). The spectrometer was tuned to obtain a maximum response for $m / z$ 70-700. Elemental analyses were performed on an EA 1108 Elemental Analyser (Fisons Instruments, Thermo Scientific, Waltham, MA, USA). Thin layer chromatography (TLC) were performed on pre-coated silica gel 60 F254 plates (Merck, Prague, Czech Republic) and visualized by exposure to UV light ( 254 or $366 \mathrm{~nm}$ ). Melting points were measured on a Boetius stage apparatus (WEB Analytik, Dresden, Germany) and are uncorrected.

\subsubsection{Synthesis of Compounds 3-9}

3-Bromo-2-\{[(3,4-dimethoxyphenyl)imino]methyl\}-6-methoxyphenol (3a). To a solution of aniline $\mathbf{1 a}$ (410 mg; $2.67 \mathrm{mmol})$ in anhydrous EtOH $(15 \mathrm{~mL})$ was added benzaldehyde $2 \mathrm{a}(600 \mathrm{mg} ; 2.60 \mathrm{mmol})$. The reaction mixture was stirred at reflux for $1 \mathrm{~h}$ and then slowly cooled to $0-5{ }^{\circ} \mathrm{C}$. Resultant precipitate was filtered off, washed with ice-cold EtOH (2 mL) and dried. Compound 3a (921 mg, 97\%) was obtained as an orange microcrystalline solid. Mp. $=157-159^{\circ} \mathrm{C} ;{ }^{1} \mathrm{H}-\mathrm{NMR}\left(400 \mathrm{MHz}, \mathrm{CDCl}_{3}\right) \delta=15.27(\mathrm{~s}, 1 \mathrm{H})$, $9.05(\mathrm{~s}, 1 \mathrm{H}), 7.02(\mathrm{~d}, J=8.8 \mathrm{~Hz}, 1 \mathrm{H}), 6.98-6.89(\mathrm{~m}, 3 \mathrm{H}), 6.78(\mathrm{~d}, J=8.8 \mathrm{~Hz}, 1 \mathrm{H}), 3.94(\mathrm{~s}, 3 \mathrm{H}), 3.92(\mathrm{~s}, 3 \mathrm{H})$, $3.90(\mathrm{~s}, 3 \mathrm{H}) ;{ }^{13} \mathrm{C}-\mathrm{NMR}\left(101 \mathrm{MHz}, \mathrm{CDCl}_{3}\right) \delta=160.4,154.6,149.6,148.8,148.7,140.0,121.8,116.4,115.7$, 114.7, 113.1, 111.4, 105.1, 56.2, 56.1, 56.0; HRMS (HESI, $m / z)$ : $[\mathrm{M}+\mathrm{H}]^{+}$calcd. for $\mathrm{C}_{16} \mathrm{H}_{17} \mathrm{BrNO}_{4}$, 366.0341; found 366.0335.

2-[(1,3-Benzodioxole-5-ylimino)methyl]-3-bromo-6-methoxyphenol (3c). Schiff base 3c was obtained in a similar manner to compound 3a using benzaldehyde 2a (750 mg; $3.25 \mathrm{mmol})$, aniline 1c (445 mg; $3.25 \mathrm{mmol})$ and anhydrous EtOH $(20 \mathrm{~mL})$. Compound $3 \mathrm{c}(1.09 \mathrm{~g} ; 92 \%)$ was obtained as a dark red microcrystalline solid. Mp. $=176-178{ }^{\circ} \mathrm{C} ;{ }^{1} \mathrm{H}-\mathrm{NMR}\left(400 \mathrm{MHz}, \mathrm{CDCl}_{3}\right) \delta=15.07$ (br. s, $\left.1 \mathrm{H}\right), 9.02(\mathrm{~s}, 1 \mathrm{H})$, $7.03(\mathrm{~d}, J=8.7 \mathrm{~Hz}, 1 \mathrm{H}), 6.92-6.89(\mathrm{~m}, 1 \mathrm{H}), 6.88-6.85(\mathrm{~m} \mathrm{2H}), 6.78(\mathrm{~d}, J=8.7 \mathrm{~Hz}, 1 \mathrm{H}), 6.03(\mathrm{~s}, 2 \mathrm{H})$, $3.91(\mathrm{~s}, 3 \mathrm{H}) ;{ }^{13} \mathrm{C}-\mathrm{NMR}\left(101 \mathrm{MHz}, \mathrm{CDCl}_{3}\right) \delta=160.6,154.4,148.8,148.7,147.4,141.4,122.0,116.5,116.0$, $115.9,114.9,108.7,101.8,101.5,56.3$; HRMS (HESI, $m / z)$ : $[\mathrm{M}+\mathrm{H}]^{+}$calcd. for $\mathrm{C}_{15} \mathrm{H}_{13} \mathrm{BrNO}_{4}, 350.0028$; found 350.0023 .

2-[(1,3-Benzodioxole-4-ylimino)methyl]-3-bromo-6-methoxyphenol (3d). Schiff base $\mathbf{3 d}$ was obtained in a similar manner to compound 3a using benzaldehyde $\mathbf{2 a}(572 \mathrm{mg} ; 2.48 \mathrm{mmol})$, aniline $\mathbf{1 d}(350 \mathrm{mg}$; $2.55 \mathrm{mmol})$ and anhydrous EtOH $(15 \mathrm{~mL})$. Compound $3 \mathrm{~d}(737 \mathrm{mg} ; 85 \%)$ was obtained as a pale orange microcrystalline solid. Mp. $=195-196{ }^{\circ} \mathrm{C} ;{ }^{1} \mathrm{H}-\mathrm{NMR}\left(400 \mathrm{MHz}, \mathrm{CDCl}_{3}\right) \delta=15.18(\mathrm{~s}, 1 \mathrm{H}), 9.40(\mathrm{~s}, 1 \mathrm{H})$, $7.05(\mathrm{~d}, J=8.6 \mathrm{~Hz}, 1 \mathrm{H}), 6.96-6.88(\mathrm{~m}, 2 \mathrm{H}), 6.82-6.77(\mathrm{~m}, 2 \mathrm{H}), 6.09(\mathrm{~s}, 2 \mathrm{H}), 3.92(\mathrm{~s}, 3 \mathrm{H}) ;{ }^{13} \mathrm{C}-\mathrm{NMR}$ $\left(101 \mathrm{MHz}, \mathrm{CDCl}_{3}\right) \delta=164.3,154.7,148.9,148.7,140.3,129.3,122.2,121.9,116.7,116.3,116.0,115.0,107.7$, 101.7, 56.2; HRMS (HESI, $m / z$ ): $[\mathrm{M}+\mathrm{H}]^{+}$calcd. for $\mathrm{C}_{15} \mathrm{H}_{13} \mathrm{BrNO}_{4}, 350.0028$; found 350.0022 .

3-Bromo-2-\{[(3,4-dimethoxyphenyl)amino]methyl\}-6-methoxyphenol (4a). To a suspension of the Schiff base 3a (921 mg, $2.51 \mathrm{mmol})$ in anhydrous EtOH (25 mL) was added $\mathrm{NaBH}_{4}(95 \mathrm{mg} ; 2.51 \mathrm{mmol})$. After $2 \mathrm{~h}$ of stirring at room temperature the reaction mixture was neutralized by adding an aqueous solution of $10 \% \mathrm{AcOH}(1 \mathrm{~mL})$. The suspension dissolved into solution, which was concentrated under reduced pressure. The residue was extracted with a mixture of EtOAc $(20 \mathrm{~mL})$ and water $(20 \mathrm{~mL})$. The aqueous phase was washed with EtOAc $(20 \mathrm{~mL})$. The combined EtOAc phases were dried over 
$\mathrm{Na}_{2} \mathrm{SO}_{4}$, filtered and concentrated under reduced pressure to provide a yellow crude oil $(737 \mathrm{mg}$, $80 \%)$. TLC R $\mathrm{f}_{\mathrm{f}}=0.3$ (hexane/EtOAc 10:3 v/v); ${ }^{1} \mathrm{H}-\mathrm{NMR}\left(400 \mathrm{MHz}, \mathrm{CDCl}_{3}\right) \delta=7.05(\mathrm{~d}, J=9.3 \mathrm{~Hz}, 1 \mathrm{H})$, $6.74(\mathrm{~d}, J=8.3 \mathrm{~Hz}, 1 \mathrm{H}), 6.66(\mathrm{~d}, J=8.3 \mathrm{~Hz}, 1 \mathrm{H}), 6.47(\mathrm{~d}, J=2.1 \mathrm{~Hz}, 1 \mathrm{H}), 6.37(\mathrm{dd}, J=2.1,8.3, \mathrm{~Hz}, 1 \mathrm{H})$, 5.89 (brs, 2H), 4.53 (s, 2H), $3.85(\mathrm{~s}, 3 \mathrm{H}), 3.83(\mathrm{~s}, 3 \mathrm{H}), 3.80(\mathrm{~s}, 3 \mathrm{H}) ;{ }^{13} \mathrm{C}-\mathrm{NMR}\left(101 \mathrm{MHz}, \mathrm{CDCl}_{3}\right) \delta=149.7$, 146.6, 146.2, 142.7, 141.7, 123.4, 123.2, 115.1, 112.7, 111.2, 106.1, 100.5, 56.5, 56.1, 55.7, 45.8; HRMS (HESI, $m / z):[\mathrm{M}+\mathrm{H}]^{+}$calcd. for $\mathrm{C}_{16} \mathrm{H}_{19} \mathrm{BrNO}_{4}, 368.0492$; found 368.0498.

2-[(1,3-Benzodioxole-5-ylamino)methyl]-3-bromo-6-methoxyphenol (4c). The secondary amine $4 \mathbf{c}$ was obtained in a similar manner as compound $4 \mathrm{a}$ using Schiff base $3 \mathrm{c}(1.0 \mathrm{~g} ; 2.9 \mathrm{mmol}), \mathrm{NaBH}_{4}(109 \mathrm{mg}$; $2.9 \mathrm{mmol})$ and anhydrous $\mathrm{EtOH}(25 \mathrm{~mL})$. The resulting crude product was a pale yellow oil $(1.0 \mathrm{~g}$, $99 \%)$. A sample for analysis was prepared by crystallization from toluene $(100 \mathrm{mg} / 3 \mathrm{~mL})$ and standing this solution at $-20{ }^{\circ} \mathrm{C}$. Mp. $=95-98{ }^{\circ} \mathrm{C}$ as a colorless crystalline compound; TLC $\mathrm{R}_{\mathrm{f}}=0.3$ (hexane/EtOAc 10:3 v/v); ${ }^{1} \mathrm{H}-\mathrm{NMR}\left(400 \mathrm{MHz}, \mathrm{DMSO}-d_{6}\right) \delta=9.34(\mathrm{~s}, 1 \mathrm{H}), 7.02(\mathrm{~d}, J=8.7 \mathrm{~Hz}, 1 \mathrm{H})$, $6.86(\mathrm{~d}, J=8.7 \mathrm{~Hz}, 1 \mathrm{H}), 6.64(\mathrm{~d}, J=8.2 \mathrm{~Hz}, 1 \mathrm{H}), 6.42(\mathrm{~d}, J=1.8 \mathrm{~Hz}, 1 \mathrm{H}), 6.12(\mathrm{dd}, J=8.3,2.3 \mathrm{~Hz}$, $1 \mathrm{H}), 5.82(\mathrm{~s}, 2 \mathrm{H}), 5.21(\mathrm{t}, J=5.2 \mathrm{~Hz}, 1 \mathrm{H}), 4.19(\mathrm{~d}, J=5.2 \mathrm{~Hz}, 2 \mathrm{H}), 3.79(\mathrm{~s}, 3 \mathrm{H}) ;{ }^{13} \mathrm{C}-\mathrm{NMR}(101 \mathrm{MHz}$, DMSO- $\left.d_{6}\right) \delta=147.6,147.1,146.2,144.6,138.1,124.7,122.2,115.6,112.2,108.3,103.4,99.9,95.4,56.0$, 42.9; HRMS (HESI, $m / z$ ): $[\mathrm{M}+\mathrm{H}]^{+}$calcd. for $\mathrm{C}_{15} \mathrm{H}_{15} \mathrm{BrNO}_{4}, 352.0179$; found 352.0182 .

2-[(1,3-Benzodioxole-4-ylamino)methyl]-3-bromo-6-methoxyphenol (4d). The secondary amine $4 \mathbf{d}$ was obtained in a similar manner as compound 4 a using Schiff base $3 \mathbf{d}$ (500 mg; $1.43 \mathrm{mmol}), \mathrm{NaBH}_{4}(54 \mathrm{mg}$; $1.43 \mathrm{mmol})$ and anhydrous $\mathrm{EtOH}(13 \mathrm{~mL})$. The resulting crude product was a pale yellow oil $(500 \mathrm{mg}$, $99 \%)$. A sample for analysis was prepared by crystallization from toluene $(100 \mathrm{mg} / 3 \mathrm{~mL})$ and standing this solution at $-20{ }^{\circ} \mathrm{C}$. Mp. $=89-90^{\circ} \mathrm{C}$ as a colorless crystalline compound; TLC $\mathrm{R}_{\mathrm{f}}=0.3$ (hexane/EtOAc 10:3 v/v); ${ }^{1} \mathrm{H}-\mathrm{NMR}\left(400 \mathrm{MHz}, \mathrm{CDCl}_{3}\right) \delta=7.07(\mathrm{~d}, J=8.7 \mathrm{~Hz}, 1 \mathrm{H}), 6.75(\mathrm{t}, J=8.0 \mathrm{~Hz}$, $1 \mathrm{H}), 6.68(\mathrm{~d}, J=8.7 \mathrm{~Hz}, 1 \mathrm{H}), 6.60(\mathrm{~d}, J=8.2 \mathrm{~Hz}, 1 \mathrm{H}), 6.36(\mathrm{~d}, J=7.8 \mathrm{~Hz}, 1 \mathrm{H}), 5.90(\mathrm{~s}, 2 \mathrm{H}), 4.59(\mathrm{~s}, 2 \mathrm{H})$, $3.87(\mathrm{~s}, 3 \mathrm{H}) ;{ }^{13} \mathrm{C}-\mathrm{NMR}\left(101 \mathrm{MHz}, \mathrm{CDCl}_{3}\right) \delta=147.2,146.2,145.6,134.6,132.2,123.9,123.3,122.2,115.7$, 111.1, 107.8, 100.6, 99.8, 56.1, 43.7; HRMS (HESI, $m / z$ ): $[\mathrm{M}+\mathrm{H}]^{+}$calcd. for $\mathrm{C}_{15} \mathrm{H}_{15} \mathrm{BrNO}_{4}, 352.0179$; found 352.0183 .

N-(6-Bromo-2,3-dimethoxybenzyl)-3,4-dimethoxyaniline (4e). To a solution of bromobenzaldehyde $\mathbf{2 b}$ $(1.0 \mathrm{~g} ; 4.08 \mathrm{mmol})$ and aniline $1 \mathrm{a}(644 \mathrm{mg} ; 4.20 \mathrm{mmol})$ in anhydrous toluene $(50 \mathrm{~mL})$ was added $\mathrm{NaBH}(\mathrm{OAc})_{3}(2.6 \mathrm{~g} ; 12.2 \mathrm{mmol})$. The resulting suspension was stirred at room temperature for $1 \mathrm{~h}$, and then washed with water $(2 \times 35 \mathrm{~mL})$ and brine $(1 \times 40 \mathrm{~mL})$. The aqueous phase was extracted with toluene $(1 \times 40 \mathrm{~mL})$. The combined organic extracts were dried over $\mathrm{Na}_{2} \mathrm{SO}_{4}$, filtered and concentrated under reduced pressure. To induce crystallization of the product, $\mathrm{MeOH}(8 \mathrm{~mL})$ was added to the residue. The resulting solid was filtered off, washed with cold $\mathrm{MeOH}(1 \mathrm{~mL})$ and dried. Compound 4e was obtained as a slightly pink crystalline solid $(1.19 \mathrm{~g} ; 76 \%) . \mathrm{Mp} .=79-80{ }^{\circ} \mathrm{C}$; $\mathrm{TLC} \mathrm{R}_{\mathrm{f}}=0.2$ (hexane/EtOAc 10:3 v/v); ${ }^{1} \mathrm{H}-\mathrm{NMR}\left(400 \mathrm{MHz}, \mathrm{CDCl}_{3}\right) \delta=7.26(\mathrm{~d}, J=8.8 \mathrm{~Hz}, 1 \mathrm{H}), 6.79-6.72(\mathrm{~m}, 2 \mathrm{H})$, $6.43(\mathrm{~d}, J=2.6 \mathrm{~Hz}, 1 \mathrm{H}), 6.33(\mathrm{dd}, J=8.5,2.6 \mathrm{~Hz}, 1 \mathrm{H}), 4.42(\mathrm{~s}, 2 \mathrm{H}), 4.02($ br. s, $1 \mathrm{H}), 3.87(\mathrm{~s}, 3 \mathrm{H}), 3.86(\mathrm{~s}, 3 \mathrm{H})$, $3.85(\mathrm{~s}, 3 \mathrm{H}), 3.80(\mathrm{~s}, 3 \mathrm{H}) ;{ }^{13} \mathrm{C}-\mathrm{NMR}\left(101 \mathrm{MHz}, \mathrm{CDCl}_{3}\right) \delta=152.3,149.8,148.7,142.7,141.7,132.6,128.0$, 115.2, 113.0, 112.9, 104.6, 99.5, 61.5, 56.6, 55.9, 55.7, 43.9; HRMS (HESI, $m / z):[\mathrm{M}+\mathrm{H}]^{+}$calcd. for $\mathrm{C}_{17} \mathrm{H}_{21} \mathrm{BrNO}_{4}, 382.0654$; found 382.0648 .

N-(6-Bromo-2,3-dimethoxybenzyl)-2,3-dimethoxyaniline (4f). The secondary amine $\mathbf{4 f}$ was prepared in a similar manner as the amine $4 \mathbf{e}$ using bromobenzaldehyde $\mathbf{2 b}$ (400 $\mathrm{mg} ; 1.63 \mathrm{mmol})$, aniline $\mathbf{1 b}$ (258 mg; $1.68 \mathrm{mmol})$ and $\mathrm{NaBH}(\mathrm{OAc})_{3}(1.04 \mathrm{~g} ; 4.9 \mathrm{mmol})$ in anhydrous toluene $(20 \mathrm{~mL})$. The residue was crystallized from $\mathrm{EtOH} /$ water to provide compound $\mathbf{4 f}(212 \mathrm{mg} ; 34 \%)$ as a colorless microcrystalline solid. Mp. $=52-53{ }^{\circ} \mathrm{C}$; $\mathrm{TLC} \mathrm{R}_{\mathrm{f}}=0.5$ (hexane/EtOAc 10:3 v/v); ${ }^{1} \mathrm{H}-\mathrm{NMR}\left(400 \mathrm{MHz}\right.$, DMSO- $\left.d_{6}\right) \delta=7.34$ $(\mathrm{d}, J=8.8 \mathrm{~Hz}, 1 \mathrm{H}), 6.98(\mathrm{~d}, J=8.8 \mathrm{~Hz}, 1 \mathrm{H}), 6.85(\mathrm{t}, J=8.2 \mathrm{~Hz}, 1 \mathrm{H}), 6.52(\mathrm{dd}, J=8.2,1.2 \mathrm{~Hz}, 1 \mathrm{H}), 6.33$ $(\mathrm{dd}, J=8.2,1.2 \mathrm{~Hz}, 1 \mathrm{H}), 4.85(\mathrm{t}, J=6.2 \mathrm{~Hz}, 1 \mathrm{H}), 4.33(\mathrm{~d}, J=6.2 \mathrm{~Hz}, 2 \mathrm{H}), 3.80(\mathrm{~s}, 3 \mathrm{H}), 3.77(\mathrm{~s}, 3 \mathrm{H}), 3.72$ $(\mathrm{s}, 3 \mathrm{H}), 3.60(\mathrm{~s}, 3 \mathrm{H}) ;{ }^{13} \mathrm{C}-\mathrm{NMR}\left(101 \mathrm{MHz}, \mathrm{DMSO}-d_{6}\right) \delta=152.1,148.4,141.6,135.0,131.9,127.9,124.2$, 
119.5, 114.4, 113.8, 104.7, 101.6, 61.2, 59.5, 55.9, 55.5, 42.2; HRMS (HESI $m / z):[\mathrm{M}+\mathrm{H}]^{+}$calcd. for $\mathrm{C}_{17} \mathrm{H}_{21} \mathrm{BrNO}_{4}, 382.0654$; found 382.0648 .

$\mathrm{N}$-(6-Bromo-2,3-dimethoxybenzyl)-1,3-benzodioxole-5-amine (4g). The secondary amine $4 \mathrm{~g}$ was prepared in a similar manner as the amine $4 \mathbf{e}$ using bromobenzaldehyde $\mathbf{2 b}$ (400 $\mathrm{mg} ; 1.63 \mathrm{mmol}$ ), aniline $\mathbf{1 c}$ $(231 \mathrm{mg} ; 1.68 \mathrm{mmol})$ and $\mathrm{NaBH}(\mathrm{OAc})_{3}(1.04 \mathrm{~g} ; 4.9 \mathrm{mmol})$ in anhydrous toluene $(20 \mathrm{~mL})$. The residue was crystallized from EtOH/water to provide compound $4 \mathrm{~g}(275 \mathrm{mg} ; 46 \%)$ as a pale yellow microcrystalline solid. Mp. $=74-75{ }^{\circ} \mathrm{C} ; \mathrm{TLC} \mathrm{R}_{\mathrm{f}}=0.4$ (hexane $/$ EtOAc 10:3 v/v); ${ }^{1} \mathrm{H}-\mathrm{NMR}\left(400 \mathrm{MHz}\right.$, DMSO- $\left.d_{6}\right) \delta=7.34$ $(\mathrm{d}, J=8.8 \mathrm{~Hz}, 1 \mathrm{H}), 7.00(\mathrm{~d}, J=8.8 \mathrm{~Hz}, 1 \mathrm{H}), 6.65(\mathrm{~d}, J=8.3 \mathrm{~Hz}, 1 \mathrm{H}), 6.41(\mathrm{~d}, J=2.3 \mathrm{~Hz}, 1 \mathrm{H}), 6.12$ $(\mathrm{dd}, J=8.3,2.3 \mathrm{~Hz}, 1 \mathrm{H}), 5.82(\mathrm{~s}, 2 \mathrm{H}), 5.26(\mathrm{t}, J=5.3 \mathrm{~Hz}, 1 \mathrm{H}), 4.16(\mathrm{~d}, J=5.2 \mathrm{~Hz}, 2 \mathrm{H}), 3.81(\mathrm{~s}, 3 \mathrm{H}), 3.75$ $(\mathrm{s}, 3 \mathrm{H}) ;{ }^{13} \mathrm{C}-\mathrm{NMR}\left(101 \mathrm{MHz}, \mathrm{DMSO}-d_{6}\right) \delta=152.1,148.5,147.7,144.6,138.1,132.0,127.7,115.0,113.7$, 108.4, 103.2, 99.9, 95.2, 61.1, 55.9, 43.0; HRMS (HESI $m / z$ ): $[\mathrm{M}+\mathrm{H}]^{+}$calcd. for $\mathrm{C}_{16} \mathrm{H}_{17} \mathrm{BrNO}_{4}, 366.0341$; found 366.0337 .

$\mathrm{N}$-(6-Bromo-2,3-dimethoxybenzyl)-1,3-benzodioxole-4-amine (4h). The secondary amine $4 \mathrm{~h}$ was prepared in a similar manner as the amine $4 \mathbf{e}$ using bromobenzaldehyde $\mathbf{2 b}(253 \mathrm{mg} ; 1.03 \mathbf{m m o l})$, aniline $\mathbf{1 d}$ $(142 \mathrm{mg} ; 1.04 \mathrm{mmol})$ and $\mathrm{NaBH}(\mathrm{OAc})_{3}(660 \mathrm{mg} ; 3.1 \mathrm{mmol})$ in anhydrous toluene $(12 \mathrm{~mL})$. The residue was crystallized from $\mathrm{MeOH}$ to provide compound $4 \mathrm{~h}(302 \mathrm{mg} ; 80 \%)$ as a colorless microcrystalline solid. Mp. $=90-92{ }^{\circ} \mathrm{C}$; TLC $R_{\mathrm{f}}=0.3$ (hexane $/$ EtOAc 10:3 v/v); ${ }^{1} \mathrm{H}-\mathrm{NMR}\left(400 \mathrm{MHz}\right.$, DMSO- $\left.d_{6}\right) \delta=7.33$ $(\mathrm{d}, J=8.7 \mathrm{~Hz}, 1 \mathrm{H}), 6.98(\mathrm{~d}, J=9.2 \mathrm{~Hz}, 1 \mathrm{H}), 6.65(\mathrm{t}, J=7.8 \mathrm{~Hz}, 1 \mathrm{H}), 6.46(\mathrm{~d}, J=8.2 \mathrm{~Hz}, 1 \mathrm{H}), 6.27(\mathrm{dd}$, $J=7.8,0.9 \mathrm{~Hz}, 1 \mathrm{H}), 5.90(\mathrm{~s}, 2 \mathrm{H}), 4.82(\mathrm{t}, J=6.0 \mathrm{~Hz}, 1 \mathrm{H}), 4.40(\mathrm{~d}, J=6.0 \mathrm{~Hz}, 2 \mathrm{H}), 3.80(\mathrm{~s}, 3 \mathrm{H}), 3.77(\mathrm{~s}$, $3 \mathrm{H}) ;{ }^{13} \mathrm{C}-\mathrm{NMR}\left(101 \mathrm{MHz}\right.$, DMSO- $\left.d_{6}\right) \delta=152.1,148.4,147.0,133.2,132.7,131.8,127.7,122.1,114.6,113.7$, 107.2. 100.0, 98.3, 61.0, 55.9, 42.6; HRMS (HESI $m / z$ ): $[\mathrm{M}+\mathrm{H}]^{+}$calcd. for $\mathrm{C}_{16} \mathrm{H}_{17} \mathrm{BrNO}_{4}, 366.0341$; found 366.0337 .

N-[2-(Benzyloxy)-6-bromo-3-methoxybenzyl]-3,4-dimethoxyaniline (4i). The secondary amine 4i was prepared in a similar manner as amine $4 \mathbf{e}$ using bromobenzaldehyde $\mathbf{2 c}(1.0 \mathrm{~g} ; 3.11 \mathrm{mmol})$, aniline $\mathbf{1 a}$ (491 mg; $3.21 \mathrm{mmol})$ and $\mathrm{NaBH}(\mathrm{OAc})_{3}(1.98 \mathrm{~g} ; 9.4 \mathrm{mmol})$ in anhydrous toluene $(50 \mathrm{~mL})$. The residue was crystallized from $\mathrm{MeOH}$ to provide compound $4 \mathbf{i}(1.16 \mathrm{~g} ; 81 \%)$ as a light pink microcrystalline solid. $\mathrm{Mp} .=79-81{ }^{\circ} \mathrm{C}$; $\mathrm{TLC} \mathrm{R}_{\mathrm{f}}=0.3$ (hexane $/$ EtOAc $\left.10: 3 v / v\right) ;{ }^{1} \mathrm{H}-\mathrm{NMR}\left(400 \mathrm{MHz}\right.$, DMSO- $\left.d_{6}\right) \delta=7.43-7.29$ $(\mathrm{m}, 6 \mathrm{H}), 7.03(\mathrm{~d}, J=8.8 \mathrm{~Hz}, 1 \mathrm{H}), 6.69(\mathrm{~d}, J=8.8 \mathrm{~Hz}, 1 \mathrm{H}), 6.39(\mathrm{~d}, J=8.6 \mathrm{~Hz}, 1 \mathrm{H}), 6.15(\mathrm{dd}, J=8.6,2.6 \mathrm{~Hz}$, $1 \mathrm{H}), 5.10(\mathrm{t}, J=5.6 \mathrm{~Hz}, 1 \mathrm{H}), 4.99(\mathrm{~s}, 2 \mathrm{H}), 4.17(\mathrm{~d}, J=5.4 \mathrm{~Hz}, 2 \mathrm{H}), 3.86(\mathrm{~s}, 3 \mathrm{H}), 3.61(\mathrm{~s}, 6 \mathrm{H}) ;{ }^{13} \mathrm{C}-\mathrm{NMR}$ $\left(101 \mathrm{MHz}\right.$, DMSO- $\left.d_{6}\right) \delta=152.2,149.8,147.1,143.7,140.3,137.1,132.4,128.4,128.3,128.1,127.9,115.0$, 114.4, 113.6, 103.0, 98.7, 75.1, 56.6, 56.0, 55.1, 42.9; HRMS (HESI $m / z$ ): $[\mathrm{M}+\mathrm{H}]^{+}$calcd. for $\mathrm{C}_{23} \mathrm{H}_{25} \mathrm{BrNO}_{4}$, 458.0967; found 458.0961 .

N-[2-(Benzyloxy)-6-bromo-3-methoxybenzyl]-2,3-dimethoxyaniline (4j). The secondary amine $4 \mathbf{j}$ was prepared in a similar manner as the amine $4 \mathbf{e}$ using bromobenzaldehyde $2 \mathbf{c}(900 \mathrm{mg} ; 2.80 \mathrm{mmol})$, aniline $1 \mathrm{~b}(442 \mathrm{mg} ; 2.89 \mathrm{mmol})$ and $\mathrm{NaBH}(\mathrm{OAc})_{3}(1.78 \mathrm{~g} ; 8.4 \mathrm{mmol})$ in anhydrous toluene $(45 \mathrm{~mL})$. The residue was crystallized from EtOH to provide compound $4 \mathbf{j}(758 \mathrm{mg} ; 75 \%)$ as a pale yellow microcrystalline solid. Mp. $=86-87^{\circ} \mathrm{C} ; \mathrm{TLC}_{\mathrm{f}}=0.5$ (hexane/EtOAc $\left.10 / 3 \mathrm{v} / \mathrm{v}\right) ;{ }^{1} \mathrm{H}-\mathrm{NMR}(400 \mathrm{MHz}$, DMSO- $\left._{6}\right) \delta=7.46-7.30(\mathrm{~m}, 6 \mathrm{H}), 7.02(\mathrm{~d}, J=8.8 \mathrm{~Hz}, 1 \mathrm{H}), 6.81(\mathrm{t}, J=8.2 \mathrm{~Hz}, 1 \mathrm{H}), 6.46(\mathrm{~d}, J=8.0 \mathrm{~Hz}, 1 \mathrm{H})$, $6.32(\mathrm{~d}, J=8.3 \mathrm{~Hz}, 1 \mathrm{H}), 5.01(\mathrm{~s}, 2 \mathrm{H}), 4.85(\mathrm{t}, J=6.2 \mathrm{~Hz}, 1 \mathrm{H}), 4.27(\mathrm{~d}, J=4.9 \mathrm{~Hz}, 2 \mathrm{H}), 3.85(\mathrm{~s}, 3 \mathrm{H}), 3.71$ $(\mathrm{s}, 3 \mathrm{H}), 3.55$ (s, 3H); ${ }^{13} \mathrm{C}-\mathrm{NMR}\left(101 \mathrm{MHz}, \mathrm{DMSO}-d_{6}\right) \delta=152.2,152.1,147.0,141.5,137.1,135.1,132.2$, 128.3, 128.2, 128.1, 128.0, 124.1, 114.4, 113.7, 104.6, 101.6, 74.9, 59.4, 56.0, 55.5, 42.4; HRMS (HESI $m / z$ ): $[\mathrm{M}+\mathrm{H}]^{+}$calcd. for $\mathrm{C}_{23} \mathrm{H}_{25} \mathrm{BrNO}_{4}, 458.0967$; found 458.0961 .

N-[2-(Benzyloxy)-6-bromo-3-methoxybenzyl]-1,3-benzodioxole-5-amine (4k). The secondary amine $4 \mathbf{k}$ was prepared in a similar manner as the amine $4 \mathrm{e}$ using bromobenzaldehyde $2 \mathrm{c}(600 \mathrm{mg} ; 1.87 \mathrm{mmol})$, aniline $1 \mathrm{c}(263 \mathrm{mg} ; 1.93 \mathrm{mmol})$ and $\mathrm{NaBH}(\mathrm{OAc})_{3}(1.19 \mathrm{~g} ; 5.6 \mathrm{mmol})$ in anhydrous toluene $(33 \mathrm{~mL})$. The residue was crystallized from $\mathrm{MeOH} /$ acetone/water mixture to provide compound $4 \mathbf{k}$ (791 mg; 
$96 \%$ ) as a pale brown microcrystalline solid. Mp. $=77-80{ }^{\circ} \mathrm{C} ; \mathrm{TLC} \mathrm{R}_{\mathrm{f}}=0.5$ (hexane $/$ EtOAc 10:3 v/v); ${ }^{1} \mathrm{H}-\mathrm{NMR}\left(400 \mathrm{MHz}, \mathrm{DMSO}-d_{6}\right) \delta=7.41-7.27(\mathrm{~m}, 6 \mathrm{H}), 7.04(\mathrm{~d}, J=9.1 \mathrm{~Hz}, 1 \mathrm{H}), 6.64(\mathrm{~d}, J=8.3 \mathrm{~Hz}, 1 \mathrm{H})$, $6.38(\mathrm{~d}, J=2.3 \mathrm{~Hz}, 1 \mathrm{H}), 6.08(\mathrm{dd}, J=8.3,2.3 \mathrm{~Hz}, 1 \mathrm{H}), 5.82(\mathrm{~s}, 2 \mathrm{H}), 5.23(\mathrm{t}, J=5.2 \mathrm{~Hz}, 1 \mathrm{H}), 4.98(\mathrm{~s}, 2 \mathrm{H})$, $4.12(\mathrm{~d}, J=5.4 \mathrm{~Hz}, 2 \mathrm{H}), 3.86(\mathrm{~s}, 3 \mathrm{H}) ;{ }^{13} \mathrm{C}-\mathrm{NMR}\left(101 \mathrm{MHz}, \mathrm{DMSO}-d_{6}\right) \delta=152.2,147.7,147.2,144.6$, $138.1,137.1,132.2,128.3,128.3,128.1,127.9,115.1,113.7,108.4,103.2,99.9,95.3,75.0,56.1,43.2$; HRMS $(\mathrm{HESI} m / z):[\mathrm{M}+\mathrm{H}]^{+}$calcd. for $\mathrm{C}_{22} \mathrm{H}_{21} \mathrm{BrNO}_{4}, 442.0654$; found 442.0648 .

N-[2-(Benzyloxy)-6-bromo-3-methoxybenzyl]-1,3-benzodioxole-4-amine (41). The secondary amine 41 was prepared in a similar manner as the amine $4 \mathbf{e}$ using bromobenzaldehyde $2 \mathrm{c}(1.0 \mathrm{~g} ; 3.11 \mathrm{mmol})$, aniline $1 \mathrm{~d}$ (439 mg; $3.20 \mathrm{mmol})$ and $\mathrm{NaBH}(\mathrm{OAc})_{3}(1.98 \mathrm{~g} ; 9.3 \mathrm{mmol})$ in anhydrous toluene $(45 \mathrm{~mL})$. The residue was crystallized from EtOH to provide compound $41(1.24 \mathrm{~g} ; 90 \%)$ as a white microcrystalline solid. Mp. $=94-96{ }^{\circ} \mathrm{C} ;$ TLC $R_{\mathrm{f}}=0.4$ (toluene); ${ }^{1} \mathrm{H}-\mathrm{NMR}\left(400 \mathrm{MHz}, \mathrm{DMSO}-d_{6}\right) \delta=7.41-7.31(\mathrm{~m}, 6 \mathrm{H}), 7.03$ $(\mathrm{d}, J=9.6 \mathrm{~Hz}, 1 \mathrm{H}), 6.62(\mathrm{t}, J=8.3 \mathrm{~Hz}, 1 \mathrm{H}), 6.41(\mathrm{~d}, J=7.6 \mathrm{~Hz}, 1 \mathrm{H}), 6.26(\mathrm{~d}, J=7.6 \mathrm{~Hz}, 1 \mathrm{H}), 5.86(\mathrm{~s}, 2 \mathrm{H})$, $5.01(\mathrm{~s}, 2 \mathrm{H}), 4.75(\mathrm{t}, J=6.0 \mathrm{~Hz}, 1 \mathrm{H}), 4.33(\mathrm{~d}, J=6.0 \mathrm{~Hz}, 2 \mathrm{H}), 3.85(\mathrm{~s}, 3 \mathrm{H}) ;{ }^{13} \mathrm{C}-\mathrm{NMR}\left(101 \mathrm{MHz}, \mathrm{DMSO}-d_{6}\right)$ $\delta=152.2,147.1,147.0,137.1,133.2,132.7,132.1,128.3(2 \times), 128.1,127.9,122.1,114.7,113.8,107.3,100.0$, 98.4, 74.9, 56.1, 42.7; HRMS (HESI $m / z$ ): $[\mathrm{M}+\mathrm{H}]^{+}$calcd. for $\mathrm{C}_{22} \mathrm{H}_{21} \mathrm{BrNO}_{4}, 442.0654$; found 442.0652 .

2,3,8-Trimethoxyphenanthridin-7-ol (5a). To a suspension of benzylated phenanthridine $5 \mathbf{i}$ (52 mg; $0.14 \mathrm{mmol})$ in $\mathrm{MeOH}(8 \mathrm{~mL})$ was added $10 \% \mathrm{Pd} / \mathrm{C}(5 \mathrm{mg})$ and the mixture was vigorously stirred under atmospheric pressure of hydrogen for $4 \mathrm{~h}$. It was then filtered and concentrated under reduced pressure to afford compound $5 \mathbf{a}(28 \mathrm{mg} ; 71 \%)$ as an orange microcrystalline solid. $\mathrm{Mp} .=212-215{ }^{\circ} \mathrm{C}$; TLC $R_{\mathrm{f}}=0.2\left(\mathrm{CHCl}_{3} / \mathrm{MeOH} 40 / 2 v / v\right) ;{ }^{1} \mathrm{H}-\mathrm{NMR}\left(400 \mathrm{MHz}, \mathrm{DMSO}-d_{6}\right) \delta=9.88$ (br. s., $\left.1 \mathrm{H}\right), 9.40$ (s, $1 \mathrm{H}), 8.18(\mathrm{~d}, J=9.1 \mathrm{~Hz}, 1 \mathrm{H}), 7.98(\mathrm{~s}, 1 \mathrm{H}), 7.64(\mathrm{~d}, J=8.8 \mathrm{~Hz}, 1 \mathrm{H}), 7.47(\mathrm{~s}, 1 \mathrm{H}), 4.00(\mathrm{~s}, 3 \mathrm{H}), 3.95(\mathrm{~s}, 3 \mathrm{H})$, $3.93(\mathrm{~s}, 3 \mathrm{H}) ;{ }^{13} \mathrm{C}-\mathrm{NMR}\left(101 \mathrm{MHz}, \mathrm{DMSO}-d_{6}\right) \delta=149.9,149.3,145.5,143.7,142.7,138.7,126.4,118.0$, 117.7, 116.4, 112.8, 109.7, 102.7, 56.9, 55.9, 55.5; HRMS (HESI $m / z)$ : $[\mathrm{M}+\mathrm{H}]^{+}$calcd. for $\mathrm{C}_{16} \mathrm{H}_{16} \mathrm{NO}_{4}$ 286.1079; found 286.1074 .

3,4,8-Trimethoxyphenanthridin-7-ol $\mathbf{( 5 b )}$. Compound $\mathbf{5 b}$ was prepared in a similar manner as the base 5 a using benzylated phenanthridine $5 \mathbf{j}(20 \mathrm{mg} ; 0.09 \mathrm{mmol}), 10 \% \mathrm{Pd} / \mathrm{C}(2 \mathrm{mg})$ and $\mathrm{MeOH}$ $(4 \mathrm{~mL})$. After stirring for $4 \mathrm{~h}$ under atmospheric pressure of hydrogen, the reaction mixture was filtered. The filtrate contained both fully aromatized debenzylated product $5 \mathbf{b}$ and partially reduced debenzylated form $\mathbf{1 2 b}$ as a side product. Therefore, the mixture was vigorously stirred in air until only fully aromatized product was present (ca. $2 \mathrm{~h}$ ). The solution was allowed to stand overnight at $-20^{\circ} \mathrm{C}$ and the resulting precipitate was filtered off to afford $5 \mathbf{b}(10 \mathrm{mg} ; 66 \%)$ as an orange crystalline solid. $\mathrm{Mp} .=199-202{ }^{\circ} \mathrm{C} ; \mathrm{TLC} \mathrm{R}_{\mathrm{f}}=0.2\left(\mathrm{CHCl}_{3} / \mathrm{MeOH} 40 / 2 v / v\right) ;{ }^{1} \mathrm{H}-\mathrm{NMR}\left(400 \mathrm{MHz}, \mathrm{DMSO}-d_{6}\right) \delta=9.88$ $(\mathrm{s}, 1 \mathrm{H}), 9.51(\mathrm{~d}, J=0.5 \mathrm{~Hz}, 1 \mathrm{H}), 8.35(\mathrm{~d}, J=9.3 \mathrm{~Hz}, 1 \mathrm{H}), 8.11(\mathrm{~d}, J=9.1 \mathrm{~Hz}, 1 \mathrm{H}), 7.63(\mathrm{~d}, J=9.1 \mathrm{~Hz}$, 1H), $7.48(\mathrm{~d}, J=9.3 \mathrm{~Hz}, 1 \mathrm{H}), 3.96(\mathrm{~s}, 3 \mathrm{H}), 3.95(\mathrm{~s}, 6 \mathrm{H}) ;{ }^{13} \mathrm{C}-\mathrm{NMR}\left(101 \mathrm{MHz}, \mathrm{DMSO}-d_{6}\right) \delta=151.0,147.9$, 144.2, 144.0, 143.1, 138.0, 126.6, 118.6, 118.2, 117.7, 115.8, 114.3, 112.5, 61.2, 56.7, 56.4; HRMS (HESI $m / z)$ : $[\mathrm{M}+\mathrm{H}]^{+}$calcd. for $\mathrm{C}_{16} \mathrm{H}_{16} \mathrm{NO}_{4} 286.1079$; found 286.1074 .

3-Methoxy-[1,3]dioxolo[4,5-b]phenanthridin-4-ol (5c). Compound 5k (100 mg; $0.28 \mathrm{mmol})$ was added to ethanol $(4 \mathrm{~mL})$ containing aqueous $35 \% \mathrm{HCl}(3 \mathrm{~mL})$. This reaction mixture was heated in a sealed vial at $100{ }^{\circ} \mathrm{C}$ for $2.5 \mathrm{~h}$. After removal of volatiles, the residue was diluted with water $(5 \mathrm{~mL})$ and alkalized with aqueous $\mathrm{NH}_{3}$ solution to $\mathrm{pH}=8-9$. The precipitated solid was filtered off, washed with water and dried to provide compound $5 \mathrm{c}(57 \mathrm{mg} ; 76 \%)$ as an orange crystalline solid. A sample for analysis was prepared by crystallization from larger amount of THF. Mp. $=260-270{ }^{\circ} \mathrm{C}$ (decomp.); $\mathrm{R}_{\mathrm{f}}=0.2$ $\left(\mathrm{CHCl}_{3} / \mathrm{MeOH} 40 / 2 \mathrm{v} / v\right) ;{ }^{1} \mathrm{H}-\mathrm{NMR}\left(400 \mathrm{MHz}, \mathrm{DMSO}-d_{6}\right) \delta=9.85(\mathrm{~s}, 1 \mathrm{H}), 9.39(\mathrm{~s}, 1 \mathrm{H}), 8.14(\mathrm{~s}, 1 \mathrm{H}), 8.11$ $(\mathrm{d}, J=8.7 \mathrm{~Hz}, 1 \mathrm{H}), 7.63(\mathrm{~d}, J=9.0 \mathrm{~Hz}, 1 \mathrm{H}), 7.43(\mathrm{~s}, 1 \mathrm{H}), 6.21(\mathrm{~s}, 2 \mathrm{H}), 3.96(\mathrm{~s}, 3 \mathrm{H}) ;{ }^{13} \mathrm{C}-\mathrm{NMR}(101 \mathrm{MHz}$, DMSO- $\left.d_{6}\right) \delta=148.2,147.84,145.6,143.8,142.5,140.04,126.9,119.5,118.2,116.56,113.0,106.9,101.8$, 100.0, 56.8; HRMS (HESI m/z): $[\mathrm{M}+\mathrm{H}]^{+}$calcd. for $\mathrm{C}_{15} \mathrm{H}_{12} \mathrm{NO}_{4}, 270.0766$; found 270.0760. 
7-Methoxy-[1,3]dioxolo[4,5-c]phenanthridin-6-ol (5d). To a stirred solution of the secondary amine $4 \mathbf{d}$ ( $300 \mathrm{mg} ; 0.85 \mathrm{mmol})$ and $\mathrm{Bu}_{3} \mathrm{SnH}(460 \mu \mathrm{L} ; 1.70 \mathrm{mmol})$ in anhydrous toluene $(15 \mathrm{~mL})$ at $70{ }^{\circ} \mathrm{C}$ was added AIBN (210 mg, $1.28 \mathrm{mmol}$ ) and temperature was raised and maintained at $104-108{ }^{\circ} \mathrm{C}$ for a period of $3 \mathrm{~h}$. Due to no further conversion of starting material (4d), another portion of $\mathrm{Bu}_{3} \mathrm{SnH}$ $(160 \mu \mathrm{L} ; 0.60 \mathrm{mmol})$ and AIBN $(50 \mathrm{mg}, 0.30 \mathrm{mmol})$ were added to the reaction mixture and heating continued for a further $3 \mathrm{~h}$. The reaction mixture was then cooled to room temperature, activated $\mathrm{MnO}_{2}$ [44] (222 mg, $\left.2.56 \mathrm{mmol}\right)$ was added and stirring continued overnight. The suspension was filtered and the filtrate concentrated under reduced pressure. Addition of cyclohexane $(30 \mathrm{~mL})$ to the residue resulted in the exclusion of a red precipitate, which was filtered off and further purified by silica gel gradient column chromatography (hexane/EtOAc $5 / 1-5 / 3 v / v$ ) to afford compound $\mathbf{5 d}$ (30 mg; 13\%) as an orange microcrystalline solid. Mp. $=246-248^{\circ} \mathrm{C} ; \mathrm{R}_{\mathrm{f}}=0.2\left(\mathrm{CHCl}_{3} / \mathrm{MeOH} 40 / 2\right.$ $v / v) ;{ }^{1} \mathrm{H}-\mathrm{NMR}\left(400 \mathrm{MHz}, \mathrm{DMSO}-d_{6}\right) \delta=9.99(\mathrm{~s}, 1 \mathrm{H}), 9.44(\mathrm{~s}, 1 \mathrm{H}), 8.16(\mathrm{~d}, J=8.8 \mathrm{~Hz}, 1 \mathrm{H}), 8.08(\mathrm{~d}$, $J=8.8 \mathrm{~Hz}, 1 \mathrm{H}), 7.63(\mathrm{~d}, J=8.8 \mathrm{~Hz}, 1 \mathrm{H}), 7.35(\mathrm{~d}, J=8.8 \mathrm{~Hz}, 1 \mathrm{H}), 6.25(\mathrm{~s}, 2 \mathrm{H}), 3.95(\mathrm{~s}, 3 \mathrm{H}) ;{ }^{13} \mathrm{C}-\mathrm{NMR}$ $\left(101 \mathrm{MHz}, \mathrm{DMSO}-d_{6}\right) \delta=148.6,146.1,144.5,143.3,142.3,129.3,126.5,119.5,118.4,115.8,115.7,112.7$, 109.4, 102.0, 56.7; HRMS (HESI $m / z$ ): $[\mathrm{M}+\mathrm{H}]^{+}$calcd. for $\mathrm{C}_{15} \mathrm{H}_{12} \mathrm{NO}_{4}, 270.0766$; found 270.0761.

2,3,7,8-Tetramethoxyphenanthridin (5e). To a stirred solution of the secondary amine $4 \mathbf{e}(600 \mathrm{mg}$, $1.57 \mathrm{mmol})$ and $\mathrm{Bu}_{3} \mathrm{SnH}(845 \mu \mathrm{L} ; 3.14 \mathrm{mmol})$ in anhydrous toluene $(30 \mathrm{~mL})$ at $70{ }^{\circ} \mathrm{C}$ was added AIBN (387 mg, $2.36 \mathrm{mmol}$ ) and temperature of the reaction mixture was raised and maintained at $104-108{ }^{\circ} \mathrm{C}$ for a period of $3 \mathrm{~h}$. The reaction was carried out under an inert atmosphere of argon. After $3 \mathrm{~h}$ the reaction mixture was slowly cooled to room temperature and activated $\mathrm{MnO}_{2}(409 \mathrm{mg}$; $4.71 \mathrm{mmol}$ ) was added. The resulting mixture was stirred overnight, then filtered and concentrated under reduced pressure. Addition of cyclohexane $(8 \mathrm{~mL})$ to the residue resulted in the exclusion of a brown precipitate. The suspension was left to stand overnight at $5{ }^{\circ} \mathrm{C}$, and the next day it was filtered, washed with cyclohexane (2 mL) and recrystallized from $\mathrm{CHCl}_{3} /$ hexane. Compound $\mathbf{5 e}(185 \mathrm{mg}, 39 \%)$ was obtained as a beige crystalline solid. Mp. $=154-158{ }^{\circ} \mathrm{C}\left(\mathrm{CHCl}_{3} /\right.$ hexane $) ; \mathrm{R}_{\mathrm{f}}=0.2\left(\mathrm{CHCl}_{3} / \mathrm{MeOH}\right.$ $40 / 1 v / v) ;{ }^{1} \mathrm{H}-\mathrm{NMR}\left(400 \mathrm{MHz}, \mathrm{DMSO}-d_{6}\right) \delta=9.35(\mathrm{~s}, 1 \mathrm{H}), 8.51(\mathrm{~d}, J=8.8 \mathrm{~Hz}, 1 \mathrm{H}), 8.03(\mathrm{~s}, 1 \mathrm{H}), 7.74$ $(\mathrm{d}, J=9.1 \mathrm{~Hz}, 1 \mathrm{H}), 7.51(\mathrm{~s}, 1 \mathrm{H}), 4.02(\mathrm{~s}, 3 \mathrm{H}), 4.00(\mathrm{~s}, 6 \mathrm{H}), 3.93(\mathrm{~s}, 3 \mathrm{H}) ;{ }^{13} \mathrm{C}-\mathrm{NMR}\left(101 \mathrm{MHz}\right.$, DMSO- $\left.d_{6}\right)$ $\delta=150.1,149.6,148.9,145.0,144.1,139.0,126.4,120.2,118.9,118.5,117.6,109.8,102.6,61.4,56.6,56.0$, 55.6; HRMS (HESI $m / z$ ): $[\mathrm{M}+\mathrm{H}]^{+}$calcd. for $\mathrm{C}_{17} \mathrm{H}_{18} \mathrm{NO}_{4}, 300.1236$; found 300.1230.

3,4,7,8-Tetramethoxyphenanthridine (5f). Phenanthridine $\mathbf{5 f}$ was prepared in a similar manner as the compound 5e using amine $4 \mathrm{f}(467 \mathrm{mg} ; 1.22 \mathrm{mmol}), \mathrm{Bu}_{3} \mathrm{SnH}(660 \mu \mathrm{L} ; 2.44 \mathrm{mmol})$, AIBN (301 mg, $1.83 \mathrm{mmol})$ and $\mathrm{MnO}_{2}(318 \mathrm{mg} ; 3.66 \mathrm{mmol})$ in anhydrous toluene $(23 \mathrm{~mL})$. The recrystallization from $\mathrm{CHCl}_{3} /$ hexane afforded compound $5 \mathrm{f}(150 \mathrm{mg} ; 41 \%)$ as a beige crystalline solid. Mp. $=142-144{ }^{\circ} \mathrm{C}$; TLC $R_{\mathrm{f}}=0.2\left(\mathrm{CHCl}_{3} / \mathrm{MeOH} 40 / 1 v / v\right) ;{ }^{1} \mathrm{H}-\mathrm{NMR}\left(400 \mathrm{MHz}, \mathrm{DMSO}-d_{6}\right) \delta=9.47(\mathrm{~s}, 1 \mathrm{H}), 8.46$ $(\mathrm{d}, J=9.1 \mathrm{~Hz}, 1 \mathrm{H}), 8.42(\mathrm{~d}, J=9.1 \mathrm{~Hz}, 1 \mathrm{H}), 7.75(\mathrm{~d}, J=9.1 \mathrm{~Hz}, 1 \mathrm{H}), 7.52(\mathrm{~d}, J=9.1 \mathrm{~Hz}, 1 \mathrm{H}), 4.01$ $(\mathrm{s}, 3 \mathrm{H}), 3.99(\mathrm{~s}, 3 \mathrm{H}), 3.96(\mathrm{~s}, 6 \mathrm{H}) ;{ }^{13} \mathrm{C}-\mathrm{NMR}\left(101 \mathrm{MHz}, \mathrm{DMSO}-d_{6}\right) \delta=151.2,149.3,147.5,144.5,144.0$, 138.0, 126.7, 119.7, 119.3, 118.4, 118.2, 117.8, 114.6, 61.5, 61.3, 56.5, 56.4; HRMS (HESI $m / z)$ : $\left[\mathrm{M}+\mathrm{H}^{+}\right.$ calcd. for $\mathrm{C}_{17} \mathrm{H}_{18} \mathrm{NO}_{4}, 300.1236$; found 300.1230 .

3,4-Dimethoxy-[1,3]dioxolo[4,5-b]phenanthridine (5g). Phenanthridine $\mathbf{5 g}$ was prepared in a similar manner as compound $5 \mathbf{e}$ using secondary amine $4 \mathbf{g}(265 \mathrm{mg} ; 0.72 \mathrm{mmol}), \mathrm{Bu}_{3} \mathrm{SnH}(390 \mu \mathrm{L} ; 1.45 \mathrm{mmol})$, AIBN $(178 \mathrm{mg}, 1.09 \mathrm{mmol}), \mathrm{MnO}_{2}(189 \mathrm{mg} ; 2.17 \mathrm{mmol})$ in anhydrous toluene $(13 \mathrm{~mL})$. Compound $5 \mathrm{~g}$ (55 mg, 27\%) was obtained as a beige microcrystalline solid. Mp. $=172-174{ }^{\circ} \mathrm{C}$; TLC $\mathrm{R}_{\mathrm{f}}=0.2$ $\left(\mathrm{CHCl}_{3} / \mathrm{MeOH} 40 / 1 v / v\right) ;{ }^{1} \mathrm{H}-\mathrm{NMR}\left(400 \mathrm{MHz}, \mathrm{DMSO}-d_{6}\right) \delta=9.33(\mathrm{~d}, J=0.5 \mathrm{~Hz}, 1 \mathrm{H}), 8.44$ $(\mathrm{d}, J=9.0 \mathrm{~Hz}, 1 \mathrm{H}), 8.20(\mathrm{~s}, 1 \mathrm{H}), 7.73(\mathrm{~d}, J=9.3 \mathrm{~Hz}, 1 \mathrm{H}), 7.46(\mathrm{~s}, 1 \mathrm{H}), 6.23(\mathrm{~s}, 2 \mathrm{H}), 3.99(\mathrm{~s}, 3 \mathrm{H}), 3.98(\mathrm{~s}$, $3 \mathrm{H}) ;{ }^{13} \mathrm{C}-\mathrm{NMR}\left(101 \mathrm{MHz}\right.$, DMSO- $\left.d_{6}\right) \delta=149.0,148.4,148.1,145.2,143.9,140.2,126.9,119.5,119.5,119.1$, 118.7, 107.0, 102.0, 100.0, 61.4, 56.6; HRMS (HESI $m / z)$ : $[\mathrm{M}+\mathrm{H}]^{+}$calcd. for $\mathrm{C}_{16} \mathrm{H}_{14} \mathrm{NO}_{4}, 284.0923$; found 284.0917. 
6,7-Dimethoxy-[1,3]dioxolo[4,5-c]phenanthridine (5h). Phenanthridine $5 \mathbf{h}$ was prepared in a similar manner as the product $5 \mathbf{e}$ using amine $4 \mathrm{~h}(478 \mathrm{mg} ; 1.31 \mathrm{mmol}), \mathrm{Bu}_{3} \mathrm{SnH}(700 \mu \mathrm{L} ; 2.61 \mathrm{mmol})$, AIBN (322 mg; $1.96 \mathrm{mmol}$ ) and $\mathrm{MnO}_{2}$ (340 mg; $3.92 \mathrm{mmol}$ ) in anhydrous toluene $(23 \mathrm{~mL}$ ). The recrystallization from $\mathrm{CHCl}_{3} /$ hexane afforded compound $5 \mathrm{~h}(135 \mathrm{mg} ; 37 \%)$ as a brown crystalline solid. Mp. $=163-166{ }^{\circ} \mathrm{C}$; TLC $\mathrm{R}_{\mathrm{f}}=0.2\left(\mathrm{CHCl}_{3} / \mathrm{MeOH} 40 / 1 \mathrm{v} / v\right) ;{ }^{1} \mathrm{H}-\mathrm{NMR}\left(400 \mathrm{MHz}\right.$, DMSO- $\left.d_{6}\right)$ $\delta=9.40(\mathrm{~s}, 1 \mathrm{H}), 8.42(\mathrm{~d}, J=9.1 \mathrm{~Hz}, 1 \mathrm{H}), 8.23(\mathrm{~d}, J=8.8 \mathrm{~Hz}, 1 \mathrm{H}), 7.75(\mathrm{~d}, J=9.0 \mathrm{~Hz}, 1 \mathrm{H}), 7.39(\mathrm{~d}$, $J=8.6 \mathrm{~Hz}, 1 \mathrm{H}), 6.27(\mathrm{~s}, 2 \mathrm{H}), 4.00(\mathrm{~s}, 3 \mathrm{H}), 3.99(\mathrm{~s}, 3 \mathrm{H}) ;{ }^{13} \mathrm{C}-\mathrm{NMR}\left(101 \mathrm{MHz}, \mathrm{DMSO}-d_{6}\right) \delta=149.5,148.1$, 146.2, 144.7, 142.3, 129.1, 126.4, 122.3, 119.8, 119.5, 118.3, 115.7, 109.7, 102.1, 61.5, 56.5; HRMS (HESI $m / z)$ : $[\mathrm{M}+\mathrm{H}]^{+}$calcd. for $\mathrm{C}_{16} \mathrm{H}_{14} \mathrm{NO}_{4}, 284.0923$; found 284.0917.

7-(Benzyloxy)-2,3,8-trimethoxyphenanthridine (5i). Phenanthridine $5 \mathbf{i}$ was prepared in a similar manner as phenanthridine $5 \mathbf{e}$ using secondary amine $4 \mathbf{i}(1.27 \mathrm{~g}, 2.78 \mathrm{mmol}), \mathrm{Bu}_{3} \mathrm{SnH}(1.5 \mathrm{~mL} ; 5.55 \mathrm{mmol})$, AIBN (684 mg; $4.16 \mathrm{mmol})$ and $\mathrm{MnO}_{2}(724 \mathrm{mg}, 8.33 \mathrm{mmol})$ in anhydrous toluene $(50 \mathrm{~mL})$. The recrystallization from $\mathrm{CHCl}_{3} /$ hexane afforded compound $5 \mathbf{i}(240 \mathrm{mg} ; 23 \%)$ as a beige crystalline solid. Mp. $=155-156{ }^{\circ} \mathrm{C}$; $\mathrm{TLC} \mathrm{R}_{\mathrm{f}}=0.2\left(\mathrm{CHCl}_{3} / \mathrm{MeOH} 40 / 1 v / v\right) ;{ }^{1} \mathrm{H}-\mathrm{NMR}\left(400 \mathrm{MHz}, \mathrm{DMSO}-d_{6}\right)$ $\delta=9.25(\mathrm{~s}, 1 \mathrm{H}), 8.51(\mathrm{~d}, J=9.1 \mathrm{~Hz}, 1 \mathrm{H}), 8.01(\mathrm{~s}, 1 \mathrm{H}), 7.76(\mathrm{~d}, J=9.1 \mathrm{~Hz}, 1 \mathrm{H}), 7.53-7.49(\mathrm{~m}, 2 \mathrm{H}), 7.46$ (s, 1H), 7.41-7.30 (m, 3H), $5.25(\mathrm{~s}, 2 \mathrm{H}), 4.04(\mathrm{~s}, 3 \mathrm{H}), 4.01(\mathrm{~s}, 3 \mathrm{H}), 3.92(\mathrm{~s}, 3 \mathrm{H}) ;{ }^{13} \mathrm{C}-\mathrm{NMR}(101 \mathrm{MHz}$, DMSO- $\left.d_{6}\right) \delta=150.0,149.5,149.0,145.2,142.6,138.9,137.1,128.6,128.4,128.2,126.3,120.5,118.7,118.5$, 117.5, 109.8, 102.6, 75.0, 56.7, 56.0, 55.5; HRMS (HESI $m / z$ ): $[\mathrm{M}+\mathrm{H}]^{+}$calcd. for $\mathrm{C}_{23} \mathrm{H}_{22} \mathrm{NO}_{4}, 376.1549$; found 376.1543 .

7-(Benzyloxy)-3,4,8-trimethoxyphenanthridine (5j). Phenanthridine $5 \mathbf{j}$ was prepared in a similar manner as phenanthridine $5 \mathbf{e}$ using secondary amine $4 \mathbf{j}(950 \mathrm{mg}, 2.07 \mathrm{mmol}), \mathrm{Bu}_{3} \mathrm{SnH}(1115 \mu \mathrm{L} ; 4.15 \mathrm{mmol})$, AIBN (511 mg, $3.11 \mathrm{mmol}$ ) and $\mathrm{MnO}_{2}(541 \mathrm{mg}, 6.22 \mathrm{mmol})$ in anhydrous toluene $(37 \mathrm{~mL})$. The recrystallization from $\mathrm{CHCl}_{3} /$ hexane afforded compound $5 \mathbf{j}(233 \mathbf{m g} ; 30 \%)$ as a slightly gray microcrystalline solid. Mp. $=153-155^{\circ} \mathrm{C} ; \mathrm{TLC} \mathrm{R}_{\mathrm{f}}=0.3\left(\mathrm{CHCl}_{3} / \mathrm{MeOH} 40 / 1 v / v\right) ;{ }^{1} \mathrm{H}-\mathrm{NMR}\left(400 \mathrm{MHz}, \mathrm{DMSO}-d_{6}\right) \delta=9.38(\mathrm{~s}$, $1 \mathrm{H}), 8.45(\mathrm{~d}, J=8.8 \mathrm{~Hz}, 1 \mathrm{H}), 8.40(\mathrm{~d}, J=9.1 \mathrm{~Hz}, 1 \mathrm{H}), 7.77(\mathrm{~d}, J=9.1 \mathrm{~Hz}, 1 \mathrm{H}), 7.55-7.48(\mathrm{~m}, 3 \mathrm{H}), 7.42-7.30$ $(\mathrm{m}, 3 \mathrm{H}), 5.26(\mathrm{~s}, 2 \mathrm{H}), 4.04(\mathrm{~s}, 3 \mathrm{H}), 3.96(\mathrm{~s}, 3 \mathrm{H}), 3.93(\mathrm{~s}, 3 \mathrm{H}) ;{ }^{13} \mathrm{C}-\mathrm{NMR}\left(101 \mathrm{MHz}, \mathrm{DMSO}-d_{6}\right) \delta=151.2$, 149.4, 147.6, 143.9, 143.0, 137.9, 137.0, 128.7, 128.4, 128.2, 126.6, 120.1, 119.1, 118.3, 118.2, 117.8, 114.5, 75.1, 61.3, 56.6, 56.4; HRMS (HESI $m / z$ ): $[\mathrm{M}+\mathrm{H}]^{+}$calcd. for $\mathrm{C}_{23} \mathrm{H}_{22} \mathrm{NO}_{4}, 376.1549$; found 376.1543.

4-(Benzyloxy)-3-methoxy-[1,3]dioxolo[4,5-b]phenanthridine (5k). Phenanthridine 5k was prepared in a similar manner as phenanthridine $\mathbf{5 e}$ using secondary amine $4 \mathbf{k}(730 \mathrm{mg} ; 1.65 \mathrm{mmol}), \mathrm{Bu}_{3} \mathrm{SnH}(890 \mu \mathrm{L}$; $3.30 \mathrm{mmol})$, AIBN (407 mg, $2.48 \mathrm{mmol})$ and $\mathrm{MnO}_{2}(430 \mathrm{mg} ; 4.95 \mathrm{mmol})$ in anhydrous toluene $(29 \mathrm{~mL})$. The recrystallization from $\mathrm{CHCl}_{3} /$ hexane afforded compound $5 \mathbf{k}(280 \mathrm{mg} ; 47 \%)$ as a brown crystalline solid. Mp. $=129-131{ }^{\circ} \mathrm{C}$; TLC $\mathrm{R}_{\mathrm{f}}=0.3\left(\mathrm{CHCl}_{3} / \mathrm{MeOH} 40 / 1 v / v\right) ;{ }^{1} \mathrm{H}-\mathrm{NMR}\left(400 \mathrm{MHz}\right.$, DMSO- $\left.d_{6}\right)$ $\delta=9.25(\mathrm{~s}, 1 \mathrm{H}), 8.43(\mathrm{~d}, J=9.1 \mathrm{~Hz}, 1 \mathrm{H}), 8.18(\mathrm{~s}, 1 \mathrm{H}), 7.76(\mathrm{~d}, J=9.1 \mathrm{~Hz}, 1 \mathrm{H}), 7.53-7.49(\mathrm{~m}, 2 \mathrm{H}), 7.43-7.31$ $(\mathrm{m}, 4 \mathrm{H}), 6.21(\mathrm{~s}, 2 \mathrm{H}), 5.24(\mathrm{~s}, 2 \mathrm{H}), 4.03(\mathrm{~s}, 3 \mathrm{H}) ;{ }^{13} \mathrm{C}-\mathrm{NMR}\left(101 \mathrm{MHz}, \mathrm{DMSO}-d_{6}\right) \delta=149.1,148.4,148.0$, 145.4, 142.4, 140.0, 137.0, 128.6, 128.4, 128.2, 126.7, 120.6, 119.3, 118.9, 118.6, 106.9, 101.9, 99.9, 75.0, 56.6; HRMS (HESI $m / z$ ): $[\mathrm{M}+\mathrm{H}]^{+}$calcd. for $\mathrm{C}_{22} \mathrm{H}_{18} \mathrm{NO}_{4}, 360.1236$; found 360.1230.

6-(Benzyloxy)-7-methoxy-[1,3]dioxolo[4,5-c]phenanthridine (51). Phenanthridine 51 was prepared in a similar manner as phenanthridine $5 e$ using secondary amine $4 \mathbf{l}(1.1 \mathrm{~g} ; 2.48 \mathrm{mmol}), \mathrm{Bu}_{3} \mathrm{SnH}(1.34 \mathrm{~mL}$; $4.95 \mathrm{mmol}), \mathrm{AIBN}(610 \mathrm{mg}, 3.72 \mathrm{mmol})$ and $\mathrm{MnO}_{2}(645 \mathrm{mg} ; 7.42 \mathrm{mmol})$ in anhydrous toluene $(40 \mathrm{~mL})$. The recrystallization from $\mathrm{CHCl}_{3} /$ hexane afforded compound 51 ( $555 \mathrm{mg} ; 62 \%$ ) as a beige crystalline solid. Mp. $=163-164{ }^{\circ} \mathrm{C} ; \mathrm{TLC} \mathrm{R}_{\mathrm{f}}=0.3\left(\mathrm{CHCl}_{3} / \mathrm{MeOH} 40 / 1 v / v\right) ;{ }^{1} \mathrm{H}-\mathrm{NMR}\left(400 \mathrm{MHz}, \mathrm{DMSO}-d_{6}\right) \delta=9.27$ $(\mathrm{s}, 1 \mathrm{H}), 8.42(\mathrm{~d}, J=9.1 \mathrm{~Hz}, 1 \mathrm{H}), 8.21(\mathrm{~d}, J=8.7 \mathrm{~Hz}, 1 \mathrm{H}), 7.78(\mathrm{~d}, J=9.1 \mathrm{~Hz}, 1 \mathrm{H}), 7.50(\mathrm{~d}, J=6.9 \mathrm{~Hz}, 2 \mathrm{H})$, $7.41-7.30(\mathrm{~m}, 4 \mathrm{H}), 6.25(\mathrm{~s}, 2 \mathrm{H}), 5.26(\mathrm{~s}, 2 \mathrm{H}), 4.04(\mathrm{~s}, 3 \mathrm{H}) ;{ }^{13} \mathrm{C}-\mathrm{NMR}\left(101 \mathrm{MHz}, \mathrm{DMSO}-d_{6}\right) \delta=149.62$, 148.32, 146.25, 143.13, 142.34, 136.87, 129.06, 128.77, 128.40, 128.28, 126.38, 120.24, 119.31, 119.10, 118.41, 115.68, 109.71, 102.07, 75.07, 56.56; HRMS (HESI $m / z)$ : $[\mathrm{M}+\mathrm{H}]^{+}$calcd. for $\mathrm{C}_{22} \mathrm{H}_{18} \mathrm{NO}_{4}, 360.1236$; found 360.1230 . 
3.1.3. General Procedure for the Preparation of Phenanthridine Hydrochlorides $\mathbf{6 a - 6 1}$

The above prepared phenanthridine derivatives 5 (ca. $20 \mathrm{mg}$ ) were dissolved in dioxane (2-3 mL). To the resulting solution a $4 \mathrm{M} \mathrm{HCl}$ in dioxane solution $(1.5 \mathrm{~mL})$ was added resulting in formation of a yellow-orange precipitate. To the suspension was added ether $(4 \mathrm{~mL})$. The precipitate was filtered off, washed with ether $(2 \mathrm{~mL})$ and dried under vacuum over $\mathrm{KOH}$. The yields of hydrochlorides 6 were within $80-95 \%$. All compounds were proved by elemental analysis; the recorded values were within $+/-0.4 \%$.

7-Hydroxy-2,3,8-trimethoxyphenanthridin-5-ium chloride (6a). Elemental analysis, calcd. for $\mathrm{C}_{16} \mathrm{H}_{16} \mathrm{ClNO}_{4}$ (321.8), C, 59.73; H, 5.01; N, 4.35; found C, 59.83; H, 5.11; N, 4.08 .

7-Hydroxy-3,4,8-trimethoxyphenanthridin-5-ium chloride (6b). Elemental analysis, calcd. for $\mathrm{C}_{16} \mathrm{H}_{16} \mathrm{ClNO}_{4}$ (321.8), C, 59.73; H, 5.01; N, 4.35; found C, 59.74; H, 4.90; N, 4.18.

4-Hydroxy-3-methoxy-[1,3]dioxolo[4,5-b]phenanthridin-6-ium chloride (6c). Elemental analysis, calcd. for $\mathrm{C}_{15} \mathrm{H}_{12} \mathrm{ClNO}_{4}$ (305.7), C, 58.93; H, 3.96; N, 4.58; found C, 58.73; H, 3.77; N, 4.88.

6-Hydroxy-7-methoxy-[1,3]dioxolo[4,5-c]phenanthridin-4-ium chloride (6d). Elemental analysis, calcd. for $\mathrm{C}_{15} \mathrm{H}_{12} \mathrm{ClNO}_{4}$ (305.7), C, 58.93; H, 3.96; N, 4.58; found C, 58.65; H, 3.98; N, 4.73.

2,3,7,8-Tetramethoxyphenanthridin-5-ium chloride (6e). Elemental analysis, calcd. for $\mathrm{C}_{17} \mathrm{H}_{18} \mathrm{ClNO}_{4}$ (335.8), C, 60.81; H, 5.40; N, 4.17; found C, 61.15; H, 5.63; N, 4.26.

3,4,7,8-Tetramethoxyphenanthridin-5-ium chloride (6f). Elemental analysis, calcd. for $\mathrm{C}_{17} \mathrm{H}_{18} \mathrm{ClNO}_{4}$ (335.8), C, 60.81; H, 5.40; N, 4.17; found C, 61.01; H, 5.31; N, 4.02.

3,4-Dimethoxy-[1,3]dioxolo[4,5-b]phenanthridin-6-ium chloride (6g). Elemental analysis, calcd. for $\mathrm{C}_{16} \mathrm{H}_{14} \mathrm{ClNO}_{4}$ (319.7), C, 60.10; $\mathrm{H}, 4.41 ; \mathrm{N}, 4.38$; found $\mathrm{C}, 60.01 ; \mathrm{H}, 4.71 ; \mathrm{N}, 4.22$.

6,7-Dimethoxy-[1,3]dioxolo[4,5-c]phenanthridin-4-ium chloride (6h). Elemental analysis, calcd. for $\mathrm{C}_{16} \mathrm{H}_{14} \mathrm{ClNO}_{4}$ (319.7), C, 60.10; H, 4.41; N, 4.38; found C, 60.24; H, 4.69; N, 4.48.

7-(Benzyloxy)-2,3,8-trimethoxyphenanthridin-5-ium chloride (6i). Elemental analysis, calcd. for $\mathrm{C}_{23} \mathrm{H}_{22} \mathrm{ClNO}_{4}$ (411.9), C, 67.07; H, 5.38; N, 3.40; found C, 67.17; H, 5.31; N, 3.46.

7-(Benzyloxy)-3,4,8-trimethoxyphenanthridin-5-ium chloride (6j). Elemental analysis, calcd. for $\mathrm{C}_{23} \mathrm{H}_{22} \mathrm{ClNO}_{4}$ (411.9), C, 67.07; H, 5.38; N, 3.40; found C, 67.22; H, 5.46; N, 3.20.

4-(Benzyloxy)-3-methoxy-[1,3]dioxolo[4,5-b]phenanthridin-6-ium chloride (6k). Elemental analysis, calcd. for $\mathrm{C}_{22} \mathrm{H}_{18} \mathrm{ClNO}_{4}(395.8), \mathrm{C}, 66.75 ; \mathrm{H}, 4.58 ; \mathrm{N}, 3.54$; found $\mathrm{C}, 66.66 ; \mathrm{H}, 4.75 ; \mathrm{N}, 3.44$.

6-(Benzyloxy)-7-methoxy-[1,3]dioxolo[4,5-c]phenanthridin-4-ium chloride (61). Elemental analysis, calcd. for $\mathrm{C}_{22} \mathrm{H}_{18} \mathrm{ClNO}_{4}$ (395.8), C, 66.75; $\mathrm{H}, 4.58 ; \mathrm{N}, 3.54$; found $\mathrm{C}, 66.58 ; \mathrm{H}, 4.80 ; \mathrm{N}, 3.32$.

4-Hydroxy-3-methoxy-6-methyl-[1,3]dioxolo[4,5-b]phenanthridin-6-ium iodide (7c). The free base 5c (20 mg; $0.08 \mathrm{mmol})$ was dissolved in $\mathrm{ACN}(10 \mathrm{~mL})$ and $\mathrm{MeI}(19 \mu \mathrm{L} ; 0.3 \mathrm{mmol})$ was added. The reaction mixture was allowed to stand at r.t. in the dark place without stirring. After 7 days, the precipitated crystalline solid was filtered and washed with cold ACN $(1 \mathrm{~mL})$ to obtain poorly soluble substance $7 \mathrm{c}(18 \mathrm{mg}$; $61 \%)$ as a dark orange crystalline solid. Mp. $=250-255{ }^{\circ} \mathrm{C} ;{ }^{1} \mathrm{H}-\mathrm{NMR}\left(400 \mathrm{MHz}, \mathrm{DMSO}-d_{6}\right) \delta=11.35$ (br. s, 1H), $9.95(\mathrm{~s}, 1 \mathrm{H}), 8.50(\mathrm{~s}, 1 \mathrm{H}), 8.35(\mathrm{~d}, J=9.0 \mathrm{~Hz}, 1 \mathrm{H}), 8.05(\mathrm{~d}, J=9.1 \mathrm{~Hz}, 1 \mathrm{H}), 7.97(\mathrm{~s}, 1 \mathrm{H}), 6.41$ $(\mathrm{s}, 2 \mathrm{H}), 4.56(\mathrm{~s}, 3 \mathrm{H}), 4.05(\mathrm{~s}, 3 \mathrm{H}) ;{ }^{13} \mathrm{C}-\mathrm{NMR}\left(101 \mathrm{MHz}, \mathrm{DMSO}-d_{6}\right) \delta=150.7,150.1,147.42,145.7,145.2$, 
130.22, 127.6, 124.0, 122.7, 114.6, 113.5, 103.71, 101.4, 98.6, 57.0, 46.1; HRMS (HESI $m / z):[\mathrm{M}-\mathrm{I}]^{+}$calcd. for $\mathrm{C}_{16} \mathrm{H}_{14} \mathrm{NO}_{4}, 284.0923$; found 284.0917; elemental analysis, calcd. for $\mathrm{C}_{16} \mathrm{H}_{14} \mathrm{INO}_{4}$ (411.2), C, 46.74; $\mathrm{H}, 3.43 ; \mathrm{N}, 3.41$; found $\mathrm{C}, 46.70 ; \mathrm{H}, 3.66 ; \mathrm{N}, 3.35$.

6-Hydroxy-7-methoxy-4-methyl-[1,3]dioxolo[4,5-c]phenanthridin-4-ium iodide (7d). The quaternary salt $7 \mathbf{d}$ was prepared in a similar manner as compound $7 \mathrm{c}$ using base $5 \mathbf{d}(10 \mathrm{mg} ; 0.04 \mathrm{mmol})$, MeI $(9 \mu \mathrm{L}$; $0.15 \mathrm{mmol})$ and $\mathrm{ACN}(3 \mathrm{~mL})$. Compound $7 \mathrm{~d}(9 \mathrm{mg} ; 61 \%)$ was obtained as a dark orange crystalline solid. Mp. $=236-239{ }^{\circ} \mathrm{C} ;{ }^{1} \mathrm{H}-\mathrm{NMR}\left(400 \mathrm{MHz}, \mathrm{DMSO}-d_{6}\right) \delta=11.52($ br. s, $1 \mathrm{H}), 9.90(\mathrm{~s}, 1 \mathrm{H}), 8.49$ $(\mathrm{d}, J=8.6 \mathrm{~Hz}, 1 \mathrm{H}), 8.26(\mathrm{~d}, J=8.8 \mathrm{~Hz}, 1 \mathrm{H}), 8.00(\mathrm{~d}, J=8.8 \mathrm{~Hz}, 1 \mathrm{H}), 7.69(\mathrm{dd}, J=1.0,8.8 \mathrm{~Hz}, 1 \mathrm{H}), 6.38$ $(\mathrm{s}, 2 \mathrm{H}), 4.65(\mathrm{~s}, 3 \mathrm{H}), 4.04(\mathrm{~s}, 3 \mathrm{H}) ;{ }^{13} \mathrm{C}-\mathrm{NMR}\left(101 \mathrm{MHz}, \mathrm{DMSO}-d_{6}\right) \delta=152.0,148.8,147.4,145.7,138.1$, 126.9, 124.2, 120.9, 120.0, 118.4, 113.7, 113.0, 112.4, 103.1, 56.8, 48.2; HRMS (HESI $m / z)$ : $\left[\mathrm{M}-\mathrm{I}^{+}\right.$calcd. $^{2}$ for $\mathrm{C}_{16} \mathrm{H}_{14} \mathrm{NO}_{4}, 284.0923$; found 284.0917; elemental analysis, calcd. for $\mathrm{C}_{16} \mathrm{H}_{14} \mathrm{INO}_{4}$ (411.2), C, 46.74; $\mathrm{H}, 3.43 ; \mathrm{N}, 3.41$; found $\mathrm{C}, 46.88 ; \mathrm{H}, 3.54 ; \mathrm{N}, 3.32$.

2,3,7,8-Tetramethoxy-5-methylphenanthridinium iodide (7e). The quaternary salt $7 \mathbf{e}$ was prepared in a similar manner as compound $7 \mathbf{d}$ using base $5 \mathbf{e}(280 \mathrm{mg}, 0.94 \mathrm{mmol})$, MeI $(230 \mu \mathrm{L} ; 3.74 \mathrm{mmol})$ and ACN (14 mL). Compound 7e (372 mg; 90\%) was obtained as a dark orange needle-like crystalline solid. Mp. $=263-266{ }^{\circ} \mathrm{C} ;{ }^{1} \mathrm{H}-\mathrm{NMR}\left(400 \mathrm{MHz}, \mathrm{DMSO}-d_{6}\right) \delta=9.96(\mathrm{~s}, 1 \mathrm{H}), 8.84(\mathrm{~d}, J=9.3 \mathrm{~Hz}, 1 \mathrm{H}), 8.33$ $(\mathrm{s}, 1 \mathrm{H}), 8.20(\mathrm{~d}, J=9.3 \mathrm{~Hz}, 1 \mathrm{H}), 7.73(\mathrm{~s}, 1 \mathrm{H}), 4.70(\mathrm{~s}, 3 \mathrm{H}), 4.13(\mathrm{~s}, 6 \mathrm{H}), 4.10(\mathrm{~s}, 6 \mathrm{H}) ;{ }^{13} \mathrm{C}-\mathrm{NMR}(101 \mathrm{MHz}$, DMSO- $\left.d_{6}\right) \delta=152.0,151.5,149.9,146.9,145.6,129.1,127.7,125.3,120.8,119.2,118.7,103.9,100.7,62.1$, 57.0, 56.8, 56.6, 46.0; HRMS (HESI $m / z$ ): $[\mathrm{M}-\mathrm{I}]^{+}$calcd. for $\mathrm{C}_{18} \mathrm{H}_{20} \mathrm{NO}_{4}, 314.1392$; found 314.1387; elemental analysis, calcd. for $\mathrm{C}_{18} \mathrm{H}_{20} \mathrm{INO}_{4}$ (441.3), C, 48.99; $\mathrm{H}, 4.57 \mathrm{~N}, 3.17$; found $\mathrm{C}, 48.92 ; \mathrm{H}, 4.15$; $\mathrm{N}, 3.12$.

3,4,7,8-Tetramethoxy-5-methylphenanthridinium iodide (7f). The quaternary salt $\mathbf{7 f}$ was prepared in a similar manner as compound $\mathbf{7 d}$ using base $\mathbf{5 f}(60 \mathrm{mg}, 0.20 \mathrm{mmol})$, MeI $(50 \mu \mathrm{L}, 0.80 \mathrm{mmol})$ and ACN ( $5 \mathrm{~mL}$ ). Compound $7 \mathrm{f}(42 \mathrm{mg} ; 47 \%)$ was obtained as an orange crystalline solid. $\mathrm{Mp} .=186-188^{\circ} \mathrm{C}$; ${ }^{1} \mathrm{H}-\mathrm{NMR}\left(400 \mathrm{MHz}, \mathrm{DMSO}-d_{6}\right) \delta=9.95(\mathrm{~s}, 1 \mathrm{H}), 8.81(\mathrm{~d}, J=9.3 \mathrm{~Hz}, 1 \mathrm{H}), 8.70(\mathrm{~d}, J=9.3 \mathrm{~Hz}, 1 \mathrm{H}), 8.19$ $(\mathrm{d}, J=9.3 \mathrm{~Hz}, 1 \mathrm{H}), 7.89(\mathrm{~d}, J=9.3 \mathrm{~Hz}, 1 \mathrm{H}), 4.81(\mathrm{~s}, 3 \mathrm{H}), 4.13(\mathrm{~s}, 3 \mathrm{H}), 4.09(\mathrm{~s}, 3 \mathrm{H}), 4.08(\mathrm{~s}, 3 \mathrm{H}), 3.99$ $(\mathrm{s}, 3 \mathrm{H}) ;{ }^{13} \mathrm{C}-\mathrm{NMR}\left(101 \mathrm{MHz}\right.$, DMSO- $\left.d_{6}\right) \delta=154.4,153.6,150.0,146.4,140.1,128.3,128.1,126.2,120.5$, 120.2, 118.5, 118.0, 116.9, 62.2, 61.8, 56.9, 51.1, 39.5; HRMS (HESI $m / z$ ): $[\mathrm{M}-\mathrm{I}]^{+}$calcd. for $\mathrm{C}_{18} \mathrm{H}_{20} \mathrm{NO}_{4}$, 314.1392; found 314.1387.

3,4-Dimethoxy-6-methyl-[1,3]dioxolo[4,5-b]phenanthridin-6-ium iodide (7g). The quaternary salt $7 \mathbf{g}$ was prepared in a similar manner as substance $7 \mathbf{d}$ using base $5 \mathbf{g}(30 \mathrm{mg}, 0.11 \mathrm{mmol}), \mathrm{MeI}(25 \mu \mathrm{L} ; 0.42 \mathrm{mmol})$ and ACN (6 mL). Compound $7 \mathrm{~g}(40 \mathrm{mg} ; 89 \%)$ was obtained as a bright yellow crystalline solid. Mp. $>300{ }^{\circ} \mathrm{C} ;{ }^{1} \mathrm{H}-\mathrm{NMR}\left(400 \mathrm{MHz}\right.$, DMSO- $\left.d_{6}\right) \delta=9.96(\mathrm{~s}, 1 \mathrm{H}), 8.71(\mathrm{~d}, J=9.3 \mathrm{~Hz}, 1 \mathrm{H}), 8.58(\mathrm{~s}, 1 \mathrm{H}), 8.19$ $(\mathrm{d}, J=9.3 \mathrm{~Hz}, 1 \mathrm{H}), 8.04(\mathrm{~s}, 1 \mathrm{H}), 6.44(\mathrm{~s}, 2 \mathrm{H}), 4.62(\mathrm{~s}, 3 \mathrm{H}), 4.11(\mathrm{~s}, 3 \mathrm{H}), 4.08(\mathrm{~s}, 3 \mathrm{H}) ;{ }^{13} \mathrm{C}-\mathrm{NMR}(101 \mathrm{MHz}$, DMSO- $\left.d_{6}\right) \delta=151.1,150.4,150.0,147.2,145.5,130.6,128.1,125.5,122.8,119.1,118.7,103.9,101.2,98.5$, 62.1, 57.0, 46.4; HRMS (HESI $m / z$ ): [M - I] ${ }^{+}$calcd. for $\mathrm{C}_{17} \mathrm{H}_{16} \mathrm{NO}_{4}, 298.1079$; found 298.1074.

6,7-Dimethoxy-4-methyl-[1,3]dioxolo[4,5-c]phenanthridin-4-ium iodide (7h). The quaternary salt $\mathbf{7 h}$ was prepared in a similar manner as the substance $7 \mathbf{d}$ using free base $5 \mathbf{h}(90 \mathrm{mg} ; 0.32 \mathrm{mmol})$, MeI $(80 \mu \mathrm{L}$; $1.27 \mathrm{mmol})$ and $\mathrm{ACN}(5 \mathrm{~mL})$. Compound $7 \mathrm{~h}(26 \mathrm{mg} ; 19 \%)$ was obtained as a blood-red crystalline solid. Mp. $=223-224{ }^{\circ} \mathrm{C} ;{ }^{1} \mathrm{H}-\mathrm{NMR}\left(400 \mathrm{MHz}, \mathrm{DMSO}-d_{6}\right) \delta=9.95(\mathrm{~s}, 1 \mathrm{H}), 8.64(\mathrm{~d}, J=9.1 \mathrm{~Hz}, 1 \mathrm{H})$, $8.59(\mathrm{~d}, J=8.8 \mathrm{~Hz}, 1 \mathrm{H}), 8.16(\mathrm{~d}, J=9.3 \mathrm{~Hz}, 1 \mathrm{H}), 7.76(\mathrm{~d}, J=8.8 \mathrm{~Hz}, 1 \mathrm{H}), 6.42(\mathrm{~s}, 2 \mathrm{H}), 4.71(\mathrm{~s}, 3 \mathrm{H}), 4.11$ $(\mathrm{s}, 3 \mathrm{H}), 4.07(\mathrm{~s}, 3 \mathrm{H}) ;{ }^{13} \mathrm{C}-\mathrm{NMR}\left(101 \mathrm{MHz}, \mathrm{DMSO}-d_{6}\right) \delta=152.1,150.2,149.1,146.7,138.2,127.6,126.0$, $120.9,120.2,118.7,118.6,118.0,112.8,103.3,62.2,56.9,48.7$; HRMS (HESI $m / z)$ : $[\mathrm{M}-\mathrm{I}]^{+}$calcd. for $\mathrm{C}_{17} \mathrm{H}_{16} \mathrm{NO}_{4}, 298.1079$; found 298.1074 . 
7-(Benzyloxy)-2,3,8-trimethoxy-5-methylphenanthridinium iodide (7i). The quaternary salt 7i was prepared in a similar manner as compound $7 \mathbf{d}$ using free base $5 \mathbf{i}(91 \mathrm{mg} ; 0.24 \mathrm{mmol}), \mathrm{MeI}(60 \mu \mathrm{L} ; 0.97 \mathrm{mmol})$ and ACN (9 mL). Compound $7 \mathbf{i}(77 \mathrm{mg} ; 61 \%)$ was obtained as a bright yellow crystalline solid. Mp. $=207-210{ }^{\circ} \mathrm{C} ;{ }^{1} \mathrm{H}-\mathrm{NMR}\left(400 \mathrm{MHz}, \mathrm{DMSO}-d_{6}\right) \delta=9.79(\mathrm{~s}, 1 \mathrm{H}), 8.83(\mathrm{~d}, J=9.3 \mathrm{~Hz}, 1 \mathrm{H}), 8.30(\mathrm{~s}, 1 \mathrm{H})$, $8.20(\mathrm{~d}, J=9.1 \mathrm{~Hz}, 1 \mathrm{H}), 7.70(\mathrm{~s}, 1 \mathrm{H}), 7.58(\mathrm{~d}, J=7.5 \mathrm{~Hz}, 2 \mathrm{H}), 7.43-7.30(\mathrm{~m}, 3 \mathrm{H}), 5.40(\mathrm{~s}, 2 \mathrm{H}), 4.68(\mathrm{~s}, 3 \mathrm{H})$, $4.12(\mathrm{~s}, 6 \mathrm{H}), 4.09$ (s, 3H); ${ }^{13} \mathrm{C}-\mathrm{NMR}\left(101 \mathrm{MHz}, \mathrm{DMSO}-d_{6}\right) \delta=152.0,151.5,150.2,146.7,143.9,136.3$, $128.9,128.9,128.4,128.3,127.5,125.0,120.7,119.4,119.1,103.9,100.7,75.4,57.0,56.7,56.6,46.2$; HRMS (HESI m/z): [M - I] ${ }^{+}$calcd. for $\mathrm{C}_{24} \mathrm{H}_{24} \mathrm{NO}_{4}, 390.1705$; found 390.1700 .

7-(Benzyloxy)-3,4,8-trimethoxy-5-methylphenanthridinium iodide (7j). The quaternary salt $\mathbf{7 j}$ was prepared in a similar manner as compound $\mathbf{7 d}$ using free base $5 \mathbf{j}(150 \mathrm{mg} ; 0.40 \mathrm{mmol}), \mathrm{MeI}(100 \mu \mathrm{L} ; 1.6 \mathrm{mmol})$ and ACN (7 mL). Compound $7 \mathbf{j}(123 \mathrm{mg} ; 60 \%)$ was obtained as a light orange microcrystalline solid. Mp. $=169-173{ }^{\circ} \mathrm{C} ;{ }^{1} \mathrm{H}-\mathrm{NMR}\left(400 \mathrm{MHz}, \mathrm{DMSO}-d_{6}\right) \delta=9.79(\mathrm{~s}, 1 \mathrm{H}), 8.80(\mathrm{~d}, J=9.3 \mathrm{~Hz}, 1 \mathrm{H}), 8.70$ $(\mathrm{d}, J=9.1 \mathrm{~Hz}, 1 \mathrm{H}), 8.20(\mathrm{~d}, J=9.1 \mathrm{~Hz}, 1 \mathrm{H}), 7.89(\mathrm{~d}, J=9.3 \mathrm{~Hz}, 1 \mathrm{H}), 7.59(\mathrm{~d}, J=7.0 \mathrm{~Hz}, 2 \mathrm{H}), 7.48-7.26$ $(\mathrm{m}, 3 \mathrm{H}), 5.41(\mathrm{~s}, 2 \mathrm{H}), 4.79(\mathrm{~s}, 3 \mathrm{H}), 4.10(\mathrm{~s}, 3 \mathrm{H}), 4.08(\mathrm{~s}, 3 \mathrm{H}), 3.98(\mathrm{~s}, 3 \mathrm{H}) ;{ }^{13} \mathrm{C}-\mathrm{NMR}\left(101 \mathrm{MHz}, \mathrm{DMSO}-d_{6}\right)$ $\delta=154.4,153.5,150.3,144.6,140.1,136.3,128.9,128.4,128.3,128.2,127.9,126.0,120.4,120.2,118.8$, 118.5, 117.0, 75.6, 61.8, 57.0, 56.9, 51.3; HRMS (HESI $m / z$ ): $[\mathrm{M}-\mathrm{I}]^{+}$calcd. for $\mathrm{C}_{24} \mathrm{H}_{24} \mathrm{NO}_{4}, 390.1705$; found 390.1700 .

4-(Benzyloxy)-3-methoxy-6-methyl-[1,3]dioxolo[4,5-b]phenanthridin-6-ium iodide (7k). The quaternary salt $\mathbf{7 k}$ was prepared in a similar manner as compound 7d using free base 5k (91 mg, $0.25 \mathrm{mmol}), \mathrm{MeI}(60 \mu \mathrm{L}$, $1.0 \mathrm{mmol})$ and $\mathrm{ACN}(8 \mathrm{~mL})$. The reaction was conducted at $50{ }^{\circ} \mathrm{C}$ for $36 \mathrm{~h}$. Compound $7 \mathrm{k}(77 \mathrm{mg} ; 61 \%)$ was obtained as a pale yellow crystalline solid. Mp. $=198-201{ }^{\circ} \mathrm{C} ;{ }^{1} \mathrm{H}-\mathrm{NMR}\left(400 \mathrm{MHz}, \mathrm{DMSO}-d_{6}\right)$ $\delta=9.81(\mathrm{~s}, 1 \mathrm{H}), 8.69(\mathrm{~d}, J=9.1 \mathrm{~Hz}, 1 \mathrm{H}), 8.55(\mathrm{~s}, 1 \mathrm{H}), 8.19(\mathrm{~d}, J=9.3 \mathrm{~Hz}, 1 \mathrm{H}), 8.01(\mathrm{~s}, 1 \mathrm{H}), 7.61-7.56$ $(\mathrm{m}, 2 \mathrm{H}), 7.42-7.31(\mathrm{~m}, 3 \mathrm{H}), 6.44(\mathrm{~s}, 2 \mathrm{H}), 5.38(\mathrm{~s}, 2 \mathrm{H}), 4.60(\mathrm{~s}, 3 \mathrm{H}), 4.10(\mathrm{~s}, 3 \mathrm{H}) ;{ }^{13} \mathrm{C}-\mathrm{NMR}(101 \mathrm{MHz}$, DMSO- $\left.d_{6}\right) \delta=151.1,150.4,150.2,147.0,143.7,136.3,130.5,128.9,128.4,128.3,128.0,125.3,122.8,119.2$, 119.2, 103.9, 101.3, 98.5, 75.4, 56.9, 46.7; HRMS (HESI $m / z$ ): $[\mathrm{M}-\mathrm{I}]^{+}$calcd. for $\mathrm{C}_{23} \mathrm{H}_{20} \mathrm{NO}_{4}, 374.1392$; found 374.1387 .

6-(Benzyloxy)-7-methoxy-4-methyl-[1,3]dioxolo[4,5-c]phenanthridin-4-ium iodide (71). The quaternary salt $7 \mathbf{l}$ was prepared in a similar manner as compound $\mathbf{7 d}$ with using free base 51 (36 $\mathrm{mg}, 0.1 \mathrm{mmol}$ ), MeI $(24 \mu \mathrm{L}, 0.4 \mathrm{mmol})$ and ACN $(4 \mathrm{~mL})$. The reaction was conducted at $50{ }^{\circ} \mathrm{C}$ for $36 \mathrm{~h}$. Compound 71 $(28 \mathrm{mg} ; 55 \%)$ was obtained as a light orange solid. Mp. $=169-172{ }^{\circ} \mathrm{C} ;{ }^{1} \mathrm{H}-\mathrm{NMR}\left(400 \mathrm{MHz}, \mathrm{DMSO}-d_{6}\right)$ $\delta=9.80(\mathrm{~s}, 1 \mathrm{H}), 8.64(\mathrm{~d}, J=9.2 \mathrm{~Hz}, 1 \mathrm{H}), 8.58(\mathrm{~d}, J=8.7 \mathrm{~Hz}, 1 \mathrm{H}), 8.17(\mathrm{~d}, J=9.2 \mathrm{~Hz}, 1 \mathrm{H}), 7.75$ $(\mathrm{d}, J=8.7 \mathrm{~Hz}, 1 \mathrm{H}), 7.64-7.52(\mathrm{~m}, 2 \mathrm{H}), 7.44-7.28(\mathrm{~m}, 3 \mathrm{H}), 6.40(\mathrm{~s}, 2 \mathrm{H}), 5.39(\mathrm{~s}, 2 \mathrm{H}), 4.69(\mathrm{~s}, 3 \mathrm{H}), 4.08(\mathrm{~s}$, $3 \mathrm{H}) ;{ }^{13} \mathrm{C}-\mathrm{NMR}\left(101 \mathrm{MHz}, \mathrm{DMSO}-d_{6}\right) \delta=152.0,150.2,149.2,145.0,138.2,136.2,128.9,128.5,128.4,127.6$, 125.8, 120.8, 120.2, 119.0, 118.6, 118.5, 112.9, 103.3, 75.6, 56.9, 48.9; HRMS (HESI m/z): [M - I] ${ }^{+}$calcd. for $\mathrm{C}_{23} \mathrm{H}_{20} \mathrm{NO}_{4}, 374.1392$; found 374.1387 .

\subsubsection{Preparation of 2,3,7,8-tetramethoxy-5-methylphenanthridinium Salts $9 t-9 z$}

To a suspension of quaternary iodide 7 e $(54 \mathrm{mg} ; 0.11 \mathrm{mmol})$ in $\mathrm{EtOH}(18 \mathrm{~mL})$ was added $1.25 \mathrm{~N}$ aqueous $\mathrm{NaOH}(180 \mu \mathrm{L} ; 0.22 \mathrm{mmol})$. After $1 \mathrm{~h}$ of stirring the resulting colorless solution was diluted with water $(2 \mathrm{~mL})$ and concentrated under reduced pressure to remove $\mathrm{EtOH}$ resulting in precipitation of a white crystalline solid (pseudobase 8), which was not isolated. To the suspension of pseudobase was added $20 \%$ aqueous solution of corresponding acid $(10 \mathrm{~mL})$ and the mixture was stirred for $10 \mathrm{~min}$, and then cooled to $0^{\circ} \mathrm{C}$. The resulting yellow precipitate was filtered, washed with ice water $(2 \mathrm{~mL})$ and dried at $110^{\circ} \mathrm{C}$.

2,3,7,8-Tetramethoxy-5-methylphenanthridinium chloride (9t): Yield $35 \mathrm{mg}(82 \%)$ as a yellow microcrystalline compound. Mp. $=220-222{ }^{\circ} \mathrm{C} ;{ }^{1} \mathrm{H}-\mathrm{NMR}\left(400 \mathrm{MHz}, \mathrm{DMSO}-d_{6}\right) \delta=9.96(\mathrm{~s}, 1 \mathrm{H})$, 
$8.83(\mathrm{~d}, J=9.2 \mathrm{~Hz}, 1 \mathrm{H}), 8.29(\mathrm{~s}, 1 \mathrm{H}), 8.17(\mathrm{~d}, J=9.3 \mathrm{~Hz}, 1 \mathrm{H}), 7.72(\mathrm{~s}, 1 \mathrm{H}), 4.71(\mathrm{~s}, 3 \mathrm{H}), 4.12(\mathrm{~s}, 3 \mathrm{H}), 4.11$ $(\mathrm{s}, 3 \mathrm{H}), 4.10(\mathrm{~s}, 3 \mathrm{H}), 4.09(\mathrm{~s}, 3 \mathrm{H}) ;{ }^{13} \mathrm{C}-\mathrm{NMR}\left(101 \mathrm{MHz}, \mathrm{DMSO}-d_{6}\right) \delta=152.0,151.5,149.9,146.8,145.6$, 129.1, 127.6, 125.2, 120.8, 119.18, 118.68, 103.9, 100.7, 62.1, 57.1, 56.7, 56.6, 46.0; elemental analysis, calcd. for $\mathrm{C}_{18} \mathrm{H}_{20} \mathrm{ClNO}_{4}(349.8), \mathrm{C}, 61.80 ; \mathrm{H}, 5.76 ; \mathrm{N}, 4.00$; found $\mathrm{C}, 61.83 ; \mathrm{H}, 5.69 ; \mathrm{N}, 4.03$.

2,3,7,8-Tetramethoxy-5-methylphenanthridinium perchlorate (9u): Yield $40 \mathrm{mg}(80 \%)$ as a light orange microcrystalline compound. Mp. $=$ above $300{ }^{\circ} \mathrm{C} ;{ }^{1} \mathrm{H}-\mathrm{NMR}\left(400 \mathrm{MHz}\right.$, DMSO- $\left.d_{6}\right) \delta=9.93(\mathrm{~s}, 1 \mathrm{H}), 8.80$ $(\mathrm{d}, J=9.2 \mathrm{~Hz}, 1 \mathrm{H}), 8.28(\mathrm{~s}, 1 \mathrm{H}), 8.17(\mathrm{~d}, J=9.3 \mathrm{~Hz}, 1 \mathrm{H}), 7.70(\mathrm{~s}, 1 \mathrm{H}), 4.69(\mathrm{~s}, 3 \mathrm{H}), 4.12(\mathrm{~s}, 3 \mathrm{H}), 4.12(\mathrm{~s}, 3 \mathrm{H})$, $4.09(\mathrm{~s}, 6 \mathrm{H}) ;{ }^{13} \mathrm{C}-\mathrm{NMR}\left(101 \mathrm{MHz}, \mathrm{DMSO}-d_{6}\right) \delta=152.0,151.5,149.9,146.8,145.6,129.1,127.6,125.2$, $120.8,119.18,118.68,103.9,100.7,62.1,57.1,56.7,56.6,46.0$; elemental analysis, calcd. for $\mathrm{C}_{18} \mathrm{H}_{20} \mathrm{ClNO}_{8}$ (413.8), C, 52.24; H, 4.87; N, 3.38; found C, 52.12; H, 4.68; N, 3.35 .

2,3,7,8-Tetramethoxy-5-methylphenanthridinium hydrogensulfate $(9 \mathbf{w})$ : Yield $38 \mathrm{mg}(75 \%)$ as a yellow microcrystalline compound. Mp. $=272-280{ }^{\circ} \mathrm{C} ;{ }^{1} \mathrm{H}-\mathrm{NMR}\left(400 \mathrm{MHz}, \mathrm{DMSO}-d_{6}\right) \delta=9.94(\mathrm{~s}, 1 \mathrm{H}), 8.82(\mathrm{~d}$, $J=9.2 \mathrm{~Hz}, 1 \mathrm{H}), 8.30(\mathrm{~s}, 1 \mathrm{H}), 8.18(\mathrm{~d}, J=9.3 \mathrm{~Hz}, 1 \mathrm{H}), 7.72(\mathrm{~s}, 1 \mathrm{H}), 4.70(\mathrm{~s}, 3 \mathrm{H}), 4.12(\mathrm{~s}, 3 \mathrm{H}), 4.12(\mathrm{~s}, 3 \mathrm{H})$, $4.10(\mathrm{~s}, 3 \mathrm{H}), 4.09(\mathrm{~s}, 3 \mathrm{H}) ;{ }^{13} \mathrm{C}-\mathrm{NMR}\left(101 \mathrm{MHz}, \mathrm{DMSO}-d_{6}\right) \delta=152.0,151.5,149.9,146.8,145.6,129.1$, 127.6, 125.2, 120.8, 119.18, 118.68, 103.9, 100.7, 62.1, 57.1, 56.7, 56.6, 46.0; elemental analysis, calcd. for $\mathrm{C}_{18} \mathrm{H}_{21} \mathrm{NO}_{8} \mathrm{~S}$ (411.4), $\mathrm{C}, 52.55 ; \mathrm{H}, 5.14 ; \mathrm{N}, 3.40$; found $\mathrm{C}, 52.40 ; \mathrm{H}, 5.24 ; \mathrm{N}, 3.43$.

2,3,7,8-Tetramethoxy-5-methylphenanthridinium nitrate (9z): Yield $37 \mathrm{mg}(80 \%)$ as a light orange microcrystalline compound. Mp. $=266-269{ }^{\circ} \mathrm{C} ;{ }^{1} \mathrm{H}-\mathrm{NMR}\left(400 \mathrm{MHz}, \mathrm{DMSO}-d_{6}\right) \delta=9.95(\mathrm{~s}, 1 \mathrm{H})$, $8.83(\mathrm{~d}, J=9.2 \mathrm{~Hz}, 1 \mathrm{H}), 8.32(\mathrm{~s}, 1 \mathrm{H}), 8.19(\mathrm{~d}, J=9.3 \mathrm{~Hz}, 1 \mathrm{H}), 7.72(\mathrm{~s}, 1 \mathrm{H}), 4.70(\mathrm{~s}, 3 \mathrm{H}), 4.12(\mathrm{~s}, 6 \mathrm{H}), 4.10$ $(\mathrm{s}, 6 \mathrm{H}) ;{ }^{13} \mathrm{C}-\mathrm{NMR}\left(101 \mathrm{MHz}\right.$, DMSO- $\left.d_{6}\right) \delta=152.0,151.5,149.9,146.8,145.6,129.1,127.6,125.2,120.8$, $119.18,118.68,103.9,100.7,62.1,57.1,56.7,56.6,46.0$; elemental analysis, calcd. for $\mathrm{C}_{18} \mathrm{H}_{20} \mathrm{~N}_{2} \mathrm{O}_{7}$ (376.1), C, 57.44; H, 5.36; N, 7.44; found C, 57.36; H, 5.45; N, 7.48.

\subsection{Antibacterial Activity Testing}

\subsubsection{Agar Diffusion Test}

Overnight cultures of test organisms were grown in LB broth for 18-24 $\mathrm{h}$ and standard suspensions of $1.5 \times 10^{8} \mathrm{CFU} / \mathrm{mL}$ were prepared in a sterile saline solution $(0.9 \% \mathrm{NaCl})$ according to a $\mathrm{BaSO}_{4} 0.5$ McFarland Standard. The standardized suspension $(0.1 \mathrm{~mL})$ was added to $34 \mathrm{~mL}$ of sterile, melted and tempered $\left(47-50^{\circ} \mathrm{C}\right)$ Mueller-Hinton No. 2 agar. After gentle mixing, the inoculated melted agar was poured into a sterile Petri dish $(145 \mathrm{~mm} \times 20 \mathrm{~mm}$, Greiner Bio-One, Kremsmünster, Austria) and allowed to solidify next to the flame with lids slightly ajar. Wells of $9 \mathrm{~mm}$ diameter were cut from the Petri dish agar and filled with $50 \mu \mathrm{L}$ of the test sample solution. Solutions were made at $20 \mathrm{mM}$ in DMSO and diluted in $\mathrm{MeOH}$ to $2 \mathrm{mM}$. The Petri dish was incubated at $37^{\circ} \mathrm{C}$ for $18-24 \mathrm{~h}$ and the inhibition zone diameters were measured $(\mathrm{mm})$ with an electronic caliper after $24-48 \mathrm{~h}$.

\subsubsection{MIC Determination}

Antibacterial activity of the compounds was determined by measuring their minimum inhibitory concentrations (MIC) using the broth microdilution method. Each well of a 96-well microtiter plate was filled with $50 \mu \mathrm{L}$ of sterile iron deficient $\mathrm{MH} 2$ broth. Each test compound was dissolved in DMSO making a $10 \mathrm{mM}$ solution, then diluted with sterile MH2 broth to $800 \mu \mathrm{M}$. Exactly $50 \mu \mathrm{L}$ of the compound solution was added to the first well of the microtiter plate and 2-fold serial dilutions were made down each row of the plate. A pre culture of bacteria was grown in Luria-Bertani broth overnight at $37^{\circ} \mathrm{C}$. This was diluted to McFarland standard $0.5\left(1.5 \times 10^{8} \mathrm{CFU}\right)$ with saline. $100 \mu \mathrm{L}$ of the bacterial suspension was further diluted with $14.9 \mathrm{~mL}$ of MHII broth. Exactly $50 \mu \mathrm{L}$ of bacterial (in broth) inoculum $\left(1 \times 10^{6} \mathrm{CFU} / \mathrm{mL}\right)$ was then added to each well giving a total volume of $100 \mu \mathrm{L} /$ well and $5 \times 10^{5} \mathrm{CFU} / \mathrm{mL}$ and a compound concentration gradient of $200-0.1 \mu \mathrm{M}$. The plate was incubated at 
$37^{\circ} \mathrm{C}$. After $18 \mathrm{~h}$, each well was examined visually for bacterial growth. The MIC was recorded as the lowest compound concentration required to inhibit bacterial growth as judged by turbidity relative to a row of wells diluted with a the solvent DMSO as a growth control. Ciprofloxacin was included in a control row at a concentration gradient of $5 \mu \mathrm{g} / \mathrm{mL}-0.0025 \mu \mathrm{g} / \mathrm{L}$.

\subsection{Anticancer Activity In Vitro}

The in vitro anticancer activity was determined using MCF-7 (breast adenocarcinoma) and K-562 (chronic myelogeneous leukemia) cell lines as described earlier [48]. Briefly, cells were treated in triplicate with three different doses of each compound for $72 \mathrm{~h}$. After treatments, Calcein AM solution was added, and fluoresence from live cells was measured at $485 \mathrm{~nm} / 538 \mathrm{~nm}$ (excitation/emission) using a Fluoroskan Ascent microplate reader (Thermo Scientific, Waltham, MA, USA). The EC $_{50}$ value, that is, the drug concentration reducing number of live cells to $50 \%$, was calculated from the dose response curves that resulted from the assays. The cells were maintained in DMEM medium supplemented with $10 \%$ fetal bovine serum, penicillin $(100 \mathrm{U} / \mathrm{mL})$, and streptomycin $(100 \mu \mathrm{g} / \mathrm{mL})$ and cultivated at $37^{\circ} \mathrm{C}$ in $5 \% \mathrm{CO}_{2}$.

\subsubsection{Cell Cycle Analysis}

Cell cycle analysis was performed as described earlier [48]. Briefly, subconfluent cells were treated with different concentrations of test compound for $24 \mathrm{~h}$. The cultures were pulse-labeled with $10 \mu \mathrm{M}$ 5-bromo-2'-deoxyuridine (BrdU) for $30 \mathrm{~min}$ at $37^{\circ} \mathrm{C}$ prior to harvesting. The cells were then washed in PBS, fixed with 70\% ethanol, and denatured in $2 \mathrm{M} \mathrm{HCl}$. Following neutralization, the cells were stained with anti-BrdU fluorescein-labeled antibodies, washed, stained with propidium iodide, and analyzed by flow cytometry using a $488 \mathrm{~nm}$ laser (FACSVerse, Becton Dickinson, Franklin Lakes, NJ, USA).

\subsubsection{Immunoblotting}

Immunoblotting was performed as described earlier [48]. Briefly, cellular lysates were prepared by harvesting cells in Laemmli sample buffer. Proteins were separated on SDS-polyacrylamide gels and electroblotted onto nitrocellulose membranes. After blocking, the membranes were incubated with specific primary antibodies overnight, washed and then incubated with peroxidase-conjugated secondary antibodies. Finally, peroxidase activity was detected with ECL+ reagents (AP Biotech, Prague, Czech Republic) using a LAS-4000 CCD camera (AP Biotech, Prague, Czech Republic). Specific antibodies against PARP were purchased from Santa Cruz Biotechnology (Dallas, TX, USA) peroxidase-labeled secondary antibodies was from Sigma Aldrich (Prague, Czech Republic, peroxidase-labeled secondary antibodies) or were generously gifted by Dr. B. Vojtěšek (p53, p21WAF1, PCNA).

\section{Conclusions}

In this work we extended a previously developed method for the preparation of novel phenanthridine derivatives, which were derived from benzo[c]phenanthridines by deletion of the A-ring. Derivatives were prepared with substituents on the formed skeleton that mimic biologically active benzo[c]phenanthridines. The main principle for the preparation of the aforementioned compounds was based on the radical cyclization of reduced Schiff bases prepared by the condensation of appropriate aromatic aldehydes and amines. The prepared compounds were tested for antibacterial and anticancer cytotoxic effects and compared with several compounds containing a benzo[c]phenanthridine skeleton (e.g., chelerythrine, sanguinarine, isodecarine, norchelerythrine, NK-109). Several derivatives displayed antibacterial activity against Bacillus subtilis, Micrococcus luteus and/or Mycobacterium vaccae and cytotoxicity against K-562 and MCF-7 cancer cell lines at micromolar concentrations; these compounds typically contained a $\mathrm{N}$-methylated quaternary nitrogen and 
7-benzyloxy substitution. The mechanism of action of the novel phenanthridines however remains still unclear.

Supplementary Materials: The copies of ${ }^{1} \mathrm{H}$ - and ${ }^{13} \mathrm{C}-\mathrm{NMR}$ spectra are available online.

Author Contributions: P.L. synthesized all compounds; K.M. evaluated the antimicrobial activity and analyzed the data; V.K. evaluated the anticancer activity and analyzed the data, J.S. conceived and designed the experiments and wrote the paper.

Funding: This research was funded by the Czech-National Program for Sustainability grant number LO1304, Palacky University grant numbers IGA_PrF_2018_029, IGA_LF_2018_032 and IGA_PrF_2018_006, and OP PIK grant number CZ.01.1.02/0.0/0.0/15_019/0004431.

Acknowledgments: Authors thank H. Rezková, E. Řezníčková and P. Pospíšilová for technical assistance.

Conflicts of Interest: The authors declare no conflict of interest.

\section{References}

1. Dvořák, Z.; Kubán, V.; Klejdus, B.; Vičar, J.; Ulrichová, J.; Hlaváč, J.; Šimánek, V. Quaternary benzo[c]phenanthridines sanguinarine and chelerythrine: A review of investigations from chemical and biological studies. Heterocycles 2006, 68, 2403. [CrossRef]

2. Ahsan, H.; Reagan-Shaw, S.; Breur, J.; Ahmad, N. Sanguinarine induces apoptosis of human pancreatic carcinoma AsPC-1 and BxPC-3 cells via modulations in Bcl-2 family proteins. Cancer Lett. 2007, 249, $198-208$. [CrossRef] [PubMed]

3. Jang, B.-C.; Park, J.-G.; Song, D.-K.; Baek, W.-K.; Yoo, S.K.; Jung, K.-H.; Park, G.-Y.; Lee, T.-Y.; Suh, S.-I. Sanguinarine induces apoptosis in A549 human lung cancer cells primarily via cellular glutathione depletion. Toxicol. Vitro 2009, 23, 281-287. [CrossRef] [PubMed]

4. Miao, F.; Yang, X.-J.; Zhou, L.; Hu, H.-J.; Zheng, F.; Ding, X.-D.; Sun, D.-M.; Zhou, C.-D.; Sun, W. Structural modification of sanguinarine and chelerythrine and their antibacterial activity. Nat. Prod. Res. 2011, 25, 863-875. [CrossRef] [PubMed]

5. Ishikawa, T. Benzo[c]phenanthridine bases and their antituberculosis activity. Med. Res. Rev. 2001, 21, 61-72. [CrossRef]

6. Šimánek, V. Benzophenanthridine alkaloids. In The Alkaloids; Brossi, A., Ed.; Academic Press: New York, NY, USA, 1985; Volume 26, pp. 185-240.

7. Galadari, S.; Rahman, A.; Pallichankandy, S.; Thayyullathil, F. Molecular targets and anticancer potential of sanguinarine-A benzophenanthridine alkaloid. Phytomedicine 2017, 34, 143-153. [CrossRef] [PubMed]

8. Slaninová, I.; Pěnčíková, K.; Urbanová, J.; Slanina, J.; Táborská, E. Antitumour activities of sanguinarine and related alkaloids. Phytochem. Rev. 2014, 13, 51-68. [CrossRef]

9. Maiti, M.; Nandi, R.; Chaudhuri, K. Sanguinarine: A monofunctional intercalating alkaloid. FEBS Lett. 1982, 142, 280-284. [CrossRef]

10. Wang, X.; Tanaka, M.; Krstin, S.; Peixoto, H.; Wink, M. The interference of selected cytotoxic alkaloids with the cytoskeleton: An insight into their modes of action. Molecules 2016, 21, 906. [CrossRef] [PubMed]

11. Chan, S.-L.; Lee, M.C.; Tan, K.O.; Yang, L.-K.; Lee, A.S.Y.; Flotow, H.; Fu, N.Y.; Butler, M.S.; Soejarto, D.D.; Buss, A.D.; et al. Identification of chelerythrine as an inhibitor of BclXL function. J. Biol. Chem. 2003, 278, 20453-20456. [CrossRef] [PubMed]

12. Caolo, M.A.; Stermitz, F.R. Benzophenanthridinium salt equilibria. Heterocycles 1979, 12, 11. [CrossRef]

13. Romo-Pérez, A.; Miranda, L.D.; Chávez-Blanco, A.D.; Dueñas-González, A.; del Rayo Camacho-Corona, M.; Acosta-Huerta, A.; García, A. Mild C(sp3)-H functionalization of dihydrosanguinarine and dihydrochelerythrine for development of highly cytotoxic derivatives. Eur. J. Med. Chem. 2017, 138, 1-12. [CrossRef] [PubMed]

14. Zee-Cheng, R.K.Y.; Yan, S.-J.; Cheng, C.C. Antileukemic activity of ungeremine and related compounds. Preparation of analogs of ungeremine by a practical photochemical reaction. J. Med. Chem. 1978, 21, 199-203. [CrossRef] [PubMed]

15. Hatae, N.; Fujita, E.; Shigenobu, S.; Shimoyama, S.; Ishihara, Y.; Kurata, Y.; Choshi, T.; Nishiyama, T.; Okada, C.; Hibino, S. Antiproliferative activity of O4-benzo[c]phenanthridine alkaloids against HCT-116 and HL-60 tumor cells. Bioorg. Med. Chem. Lett. 2015, 25, 2749-2752. [CrossRef] [PubMed] 
16. Nakanishi, T.; Suzuki, M.; Mashiba, A.; Ishikawa, K.; Yokotsuka, T. Synthesis of NK109, an anticancer benzo[c]phenanthridine alkaloid. J. Org. Chem. 1998, 63, 4235-4239. [CrossRef]

17. Kanzawa, F.; Nishio, K.; Ishida, T.; Fukuda, M.; Kurokawa, H.; Fukumoto, H.; Nomoto, Y.; Fukuoka, K.; Bojanowski, K.; Saijo, N. Anti-tumour activities of a new benzo[c]phenanthridine agent, 2,3-(methylenedioxy)-5-methyl-7-hydroxy-8-methoxybenzo[c]phenanthridinium hydrogensulphate dihydrate (NK109), against several drug-resistant human tumour cell lines. Br. J. Cancer 1997, 76, 571-581. [CrossRef] [PubMed]

18. Nakanishi, T.; Masuda, A.; Suwa, M.; Akiyama, Y.; Hoshino-Abe, N.; Suzuki, M. Synthesis of derivatives of NK109, 7-OH Benzo[c]phenanthridine alkaloid, and evaluation of their cytotoxicities and reduction-resistant properties. Bioorg. Med. Chem. Lett. 2000, 10, 2321-2323. [CrossRef]

19. Fukuda, M.; Inomata, M.; Nishio, K.; Fukuoka, K.; Kanzawa, F.; Arioka, H.; Ishida, T.; Fukumoto, H.; Kurokawa, H.; Oka, M.; et al. A Topoisomerase II inhibitor, NK109, induces DNA single- and double-strand breaks and apoptosis. Jpn. J. Cancer Res. 1996, 87, 1086-1091. [CrossRef] [PubMed]

20. Hisatomi, T.; Sueoka-Aragane, N.; Sato, A.; Tomimasu, R.; Ide, M.; Kurimasa, A.; Okamoto, K.; Kimura, S.; Sueoka, E. NK314 potentiates antitumor activity with adult T-cell leukemia-lymphoma cells by inhibition of dual targets on topoisomerase II and DNA-dependent protein kinase. Blood 2011, 117, 3575-3584. [CrossRef] [PubMed]

21. Toyoda, E.; Kagaya, S.; Cowell, I.G.; Kurosawa, A.; Kamoshita, K.; Nishikawa, K.; Iiizumi, S.; Koyama, H.; Austin, C.A.; Adachi, N. NK314, a topoisomerase II inhibitor that specifically targets the $\alpha$ isoform. J. Biol. Chem. 2008, 283, 23711-23720. [CrossRef] [PubMed]

22. Guo, L.; Liu, X.; Nishikawa, K.; Plunkett, W. Inhibition of topoisomerase II and G2 cell cycle arrest by NK314, a novel benzo[c]phenanthridine currently in clinical trials. Mol. Cancer Ther. 2007, 6, 1501-1508. [CrossRef] [PubMed]

23. Wang, L.K.; Johnson, R.K.; Hecht, S.M. Inhibition of topoisomerase I function by nitidine and fagaronine. Chem. Res. Toxicol. 1993, 6, 813-818. [CrossRef] [PubMed]

24. Janin, Y.L.; Bisagni, E.; Carrez, D. Synthesis of some benzo[h]quinoline derivatives. J. Heterocycl. Chem. 1993, 30, 1129-1131. [CrossRef]

25. Bernardo, P.H.; Wan, K.-F.; Sivaraman, T.; Xu, J.; Moore, F.K.; Hung, A.W.; Mok, H.Y.K.; Yu, V.C.; Chai, C.L.L. Structure-activity relationship studies of phenanthridine-based Bcl-X L inhibitors. J. Med. Chem. 2008, 51, 6699-6710. [CrossRef] [PubMed]

26. Yu, Y.; Singh, S.K.; Liu, A.; Li, T.-K.; Liu, L.F.; LaVoie, E.J. Substituted dibenzo[c, $h]$ cinnolines: Topoisomerase I-targeting anticancer agents. Bioorg. Med. Chem. 2003, 11, 1475-1491. [CrossRef]

27. Yapi, A.-D.; Desbois, N.; Chezal, J.-M.; Chavignon, O.; Teulade, J.-C.; Valentin, A.; Blache, Y. Design and preparation of aza-analogues of benzo[c]phenanthridine framework with cytotoxic and antiplasmodial activities. Eur. J. Med. Chem. 2010, 45, 2854-2859. [CrossRef] [PubMed]

28. Steinhauer, T.N.; Girreser, U.; Meier, C.; Cushman, M.; Clement, B. One-step synthetic access to isosteric and potent anticancer nitrogen heterocycles with the benzo[c]phenanthridine scaffold. Chem. A Eur. J. 2016, 22, 8301-8308. [CrossRef] [PubMed]

29. Hou, Z.; Yang, R.; Zhang, C.; Zhu, L.-F.; Miao, F.; Yang, X.-J.; Zhou, L. 2-(Substituted phenyl)3,4-dihydroisoquinolin-2-iums as novel antifungal lead compounds: Biological evaluation and structure-activity relationships. Molecules 2013, 18, 10413-10424. [CrossRef] [PubMed]

30. Yang, X.; Yao, Y.; Qin, Y.; Hou, Z.; Yang, R.; Miao, F.; Zhou, L. Synthesis and in vitro antifungal activities of new 2-aryl-6,7-methylenedioxy-3,4-dihydroisoquinolin-2-ium bromides. Chem. Pharm. Bull. 2013, 61, 731-739. [CrossRef] [PubMed]

31. Ishikawa, T.; Ishii, H. Recent advances on antitumor-active benzo[c]phenanthridine alkaloids. Heterocycles 1999, 50, 627. [CrossRef]

32. Mackay, S.P.; Meth-Cohn, O.; Waigh, R.D. Synthesis of quaternary benzo[c]phenanthridine alkaloids and their analogues. Adv. Heterocycl. Chem. 1996, 67, 345-389. [CrossRef]

33. Stýskala, J.; Cankař, P.; Soural, M.; Hradil, P.; Vičar, J.; Šimánek, V.; Hlaváč, J. Synthesis of isodecarine. Heterocycles 2007, 73, 769. [CrossRef]

34. Stýskala, J.; Hlaváč, J.; Cankař, P. Synthesis of oxidative dihydroxy metabolites of benzo[c]phenanthridines. Tetrahedron 2013, 69, 4670-4678. [CrossRef] 
35. Larghi, E.L.; Obrist, B.V.; Kaufman, T.S. A formal total synthesis of the marine alkaloid aaptamine. Tetrahedron 2008, 64, 5236-5245. [CrossRef]

36. Meisels, A.; Sondheimer, F. The constituents of casimiroa edulis llave et lex. III. 1 The structure of casimiroin 2. J. Am. Chem. Soc. 1957, 79, 6328-6333. [CrossRef]

37. Majumdar, K.; Taher, A.; Debnath, P. palladium-catalyzed intramolecular biaryl coupling: A highly efficient avenue for benzannulated pyranoquinolines and julolidine derivatives. Synthesis 2009, 2009, 793-800. [CrossRef]

38. Harayama, T.; Aktyama, T.; Kawano, K. A convenient synthesis of benzo[c]phenanthridine alkaloid, chelerythrine, by the palladium-assisted internal biaryl coupling reaction. Chem. Pharm. Bull. 1996, 44, 1634-1636. [CrossRef]

39. Campeau, L.-C.; Parisien, M.; Leblanc, M.; Fagnou, K. Biaryl synthesis via direct arylation: Establishment of an efficient catalyst for intramolecular processes. J. Am. Chem. Soc. 2004, 126, 9186-9187. [CrossRef] [PubMed]

40. Harayama, T.; Akiyama, T.; Akamatsu, H.; Kawano, K.; Abe, H.; Takeuchi, Y. Total synthesis of benzo[c]phenanthridine alkaloids, chelerythrine and 12-methoxydihydrochelerythrine, by a palladium-assisted internal biaryl coupling reaction. Synthesis 2001, 2001, 0444-0450. [CrossRef]

41. Ackermann, L. Carboxylate-assisted transition-metal-catalyzed $\mathrm{C}-\mathrm{H}$ bond functionalizations: Mechanism and scope. Chem. Rev. 2011, 111, 1315-1345. [CrossRef] [PubMed]

42. De, S.; Mishra, S.; Kakde, B.N.; Dey, D.; Bisai, A. Expeditious approach to pyrrolophenanthridones, phenanthridines, and benzo[c]phenanthridines via organocatalytic direct biaryl-coupling promoted by potassium tert -butoxide. J. Org. Chem. 2013, 78, 7823-7844. [CrossRef] [PubMed]

43. Dewanji, A.; Murarka, S.; Curran, D.P.; Studer, A. Phenyl hydrazine as initiator for direct arene C-H arylation via base promoted homolytic aromatic substitution. Org. Lett. 2013, 15, 6102-6105. [CrossRef] [PubMed]

44. Carpino, L.A. Simple preparation of active manganese dioxide from activated carbon. J. Org. Chem. 1970, 35, 3971-3972. [CrossRef]

45. Murray, P.R.; Baron, E.J.; Pfaller, M.A.; Tenover, F.C.; Yolken, R.H. Manual of Clinical Microbiology, 7th ed.; American Society for Microbiology: Washington, DC, USA, 1999.

46. Methods for Dilution Antimicrobial Susceptibility Tests for Bacteria that Grow Aerobically, 8th ed.; Approved Standard Document M07-A7; Clinical and Laboratory Standards Institute (CLSI): Villanova, PA, USA, 2009.

47. Williams, A.B.; Schumacher, B. p53 in the DNA-damage-repair process. Cold Spring Harb. Perspect. Med. 2016, 6, a026070. [CrossRef] [PubMed]

48. Zatloukal, M.; Jorda, R.; Gucký, T.; Řezníčková, E.; Voller, J.; Pospíšil, T.; Malínková, V.; Adamcová, H.; Kryštof, V.; Strnad, M. Synthesis and in vitro biological evaluation of 2,6,9-trisubstituted purines targeting multiple cyclin-dependent kinases. Eur. J. Med. Chem. 2013, 61, 61-72. [CrossRef] [PubMed]

Sample Availability: Samples of the compounds are not available.

(C) 2018 by the authors. Licensee MDPI, Basel, Switzerland. This article is an open access article distributed under the terms and conditions of the Creative Commons Attribution (CC BY) license (http:/ / creativecommons.org/licenses/by/4.0/). 